\title{
Moving forward: advances in the treatment of movement disorders with deep brain stimulation
}

\author{
Terry K. Schiefer ${ }^{1}$, Joseph Y. Matsumoto ${ }^{2}$ and Kendall H. Lee ${ }^{1 *}$ \\ ${ }^{1}$ Department of Neurologic Surgery, Mayo Clinic, Rochester, MN, USA \\ ${ }^{2}$ Department of Neurology, Mayo Clinic, Rochester, MN, USA
}

\author{
Edited by: \\ Mark Laubach, The John B. Pierce \\ Laboratory, USA
}

\section{Reviewed by:}

Gidon Felsen, University of Colorado

Medical School, USA

Nandakumar Narayanan, Yale

University, USA

*Correspondence:

Kendall H. Lee, Mayo Clinic, 200 First

Street SW, Rochester, MN 55905,

USA.

e-mail: lee.kendall@mayo.edu

The modern era of stereotactic and functional neurosurgery has ushered in state of the art technologies for the treatment of movement disorders, particularly Parkinson's disease (PD), tremor, and dystonia. After years of experience with various surgical therapies, the eventual shortcomings of both medical and surgical treatments, and several serendipitous discoveries, deep brain stimulation (DBS) has risen to the forefront as a highly effective, safe, and reversible treatment for these conditions. Idiopathic advanced PD can be treated with thalamic, globus pallidus internus (GPi), or subthalamic nucleus (STN) DBS. Thalamic DBS primarily relieves tremor while GPi and STN DBS alleviate a wide range of Parkinsonian symptoms. Thalamic DBS is also used in the treatment of other types of tremor, particularly essential tremor, with excellent results. Both primary and various types of secondary dystonia can be treated very effectively with GPi DBS. The variety of anatomical targets for these movement disorders is indicative of the network-level dysfunction mediating these movement disturbances. Despite an increasing understanding of the clinical benefits of DBS, little is known about how DBS can create such wide sweeping neuromodulatory effects. The key to improving this therapeutic modality and discovering new ways to treat these and other neurologic conditions lies in better understanding the intricacies of DBS. Here we review the history and pertinent clinical data for DBS treatment of PD, tremor, and dystonia. While multiple regions of the brain have been targeted for DBS in the treatment of these movement disorders, this review article focuses on those that are most commonly used in current clinical practice. Our search criteria for PubMed included combinations of the following terms: $D B S$, neuromodulation, movement disorders, $P D$, tremor, dystonia, and history. Dates were not restricted.

\section{Keywords: deep brain stimulation, neuromodulation, Parkinson's disease, tremor, dystonia}

\section{INTRODUCTION}

Movement disorders, particularly Parkinson's disease (PD), tremor, and dystonia, are among the most common neurological diseases. Although patients with these disorders have significantly benefited from the development of new pharmacological treatments over time, many of these therapies have either not been completely effective or not well-tolerated over the long course of the disease (Olanow and Stern, 2008; Hauser, 2009). For example, levodopa was initially felt to be the definitive treatment for PD. However, as the disease progresses it often requires escalating medication doses and frequencies to achieve the same treatment effect. This can lead to rapidly cycling motor fluctuations between

\footnotetext{
Abbreviations: ADLs, activities of daily living; BFMDRS, Burke-Fahn-Marsden Dystonia Rating Scale; CT, computed tomography; DBS, deep brain stimulation; ET, essential tremor; FDA, Food and Drug Administration; GPi, globus pallidus internus; HDE, human device exemption; HRQoL, health related quality of life; MPTP, 1-methyl-4-phenyl-1,2,3,6-tetrahydropyridine; MRI, magnetic resonance imaging; PD, Parkinson's disease; PDQ, Parkinson's Disease Questionnaire; STN, subthalamic nucleus; TWSTRS, Toronto Western Spasmodic Torticollis Rating Scale; UPDRS, Unified Parkinson's Disease Rating Scale; VIM, ventral intermediate; VL, ventral lateral; Voa, ventral oralis anterior; Vop, ventral oralis posterior; WINCS, wireless instantaneous neurotransmitter concentration system.
}

periods of mobility that may be accompanied by debilitating dyskinesias and periods of severe akinesia (Goetz et al., 2005). In response to these shortcomings, there have been significant advances over the last 15 years in stereotactic and functional neurosurgical techniques as an alternative to pharmacological therapy. These advances have led to new strategies in the treatment of movement disorders (Nandhagopal et al., 2008; Remple et al., 2008; Poewe, 2009). An increased understanding of the pathophysiology of these neurological diseases has been coupled with these technical improvements resulting in a significant increase in the application of restorative functional neurosurgical techniques to treat movement disorders. Among these newer surgical therapies, electrical stimulation of specific brain nuclei, known commonly as deep brain stimulation (DBS), has become an increasingly popular alternative strategy to traditional pharmacological treatment. DBS involves the implantation of a microelectrode into a deep target within the brain that is connected to a stimulator, which can be programmed to emit electrical impulses at varying strengths and frequencies (Figure 1). At this time, more than 80,000 people have now been successfully implanted with DBS devices worldwide, and this number is expected to grow exponentially (Medtronic, 2011). DBS is now FDA approved and is in routine clinical use for 


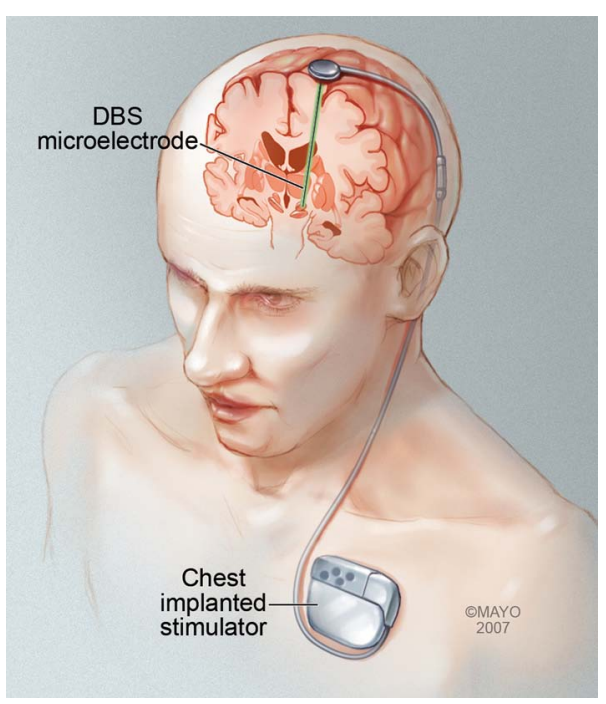

FIGURE 1 | Illustration of a DBS system with a microelectrode implanted deep within the brain. This microelectrode is connected to a programmable stimulator/battery that is typically implanted in the chest in the subclavicular space. Permission to use this image granted by Mayo Clinic.

treatment of PD, essential tremor, and dystonia (Koller et al., 2000; Lozano, 2000; Bereznai et al., 2002; Krack et al., 2002; Greene, 2005). This review will focus on DBS treatment for these three movement disorders.

\section{THE EVOLUTION OF MODERN DAY STEREOTACTIC AND FUNCTIONAL NEUROSURGERY}

The history of DBS for the treatment of movement disorders is a story marked with great triumphs, profound setbacks, and serendipitous discoveries. Early neurosurgical treatment of movement disorders focused on the treatment of PD. During the 1930s and 1940s, a large number of patients suffered from postencephalitic PD. Unfortunately, available medical therapy for this devastating condition was limited leaving surgical therapies as the main avenue of treatment. It was in this climate that the modern era of functional neurosurgery began to evolve. Initial surgical treatments were based on the premise that tremor involved motor function. Thus, if motor function was reduced or removed, the tremor should stop. Early procedures included resections of the premotor and motor cortex (Klemme, 1940; Bucy, 1942), pyramidotomy (cutting the pyramidal tracts in the high cervical spinal cord; Putnam, 1938), and pedunculotomy (incising the cerebral peduncle in the midbrain; Walker, 1952). While each of these procedures was successful to some degree in alleviating Parkinsonian tremor, they fell short as definitive treatments for two primary reasons. First, it was at the great expense of motor function; second, they had no effect on the remaining two primary symptoms of PD: akinesia and rigidity.

It was in this atmosphere that the next major breakthrough would come in the evolution of surgical treatment for movement disorders. It is said that opportunity favors the prepared mind. Such was the case for Irving Cooper. In October 1952, Cooper was performing a pedunculotomy on a 39-year-old male. During the surgical approach, an artery was torn resulting in severe bleeding. Ultimately the artery was ligated and the procedure aborted. To Cooper's surprise, upon awakening the patient had resolution of his tremor and rigidity, as well as preservation of motor function. Postoperative angiogram showed the ligated artery was the anterior choroidal artery (Das et al., 1998). Cooper (1953) concluded that ligation of this artery resulted in infarction of the medial globus pallidus and thus improved the patient's symptoms. This discovery led Cooper and others to logically turn the focus of surgical treatment of PD from the pyramidal motor system to the basal ganglia and eventually the thalamus. Lesioning techniques of these anatomical locations by mechanical means, cryotherapy, or electricity became the mainstay of surgical treatment for PD (Benabid et al., 2009). As time progressed, techniques and results improved. Indications were expanded to include tremor and dystonia. However, this new strategy still had significant drawbacks including diminishing effect over time, surgical complications, and cognitive decline when the procedures were performed bilaterally.

With these recent discoveries and developments, stereotactic functional neurosurgery for the treatment of movement disorders was exploding in the late 1950s. However, this success would be short lived and another discovery would effectively knock stereotactic functional neurosurgery from its pedestal and nearly into extinction. In 1957, through the work of Arvid Carlsson, it was discovered that cerebral dopamine was concentrated in the striatum and that levodopa could reverse reserpine induced akinesia (Carlsson et al., 1957). Ehringer and Hornykiewicz (1960) showed there was a depletion of striatal dopamine in PD patients. Ultimately, Cotzias et al. (1967) tried levodopa as an alternative to surgical therapy for PD and the initial results were nothing short of miraculous. This new therapy alleviated akinesia, rigidity, and tremor with immediate effects in a reversible and titratable manner, effectively bypassing all of the complications of surgery with better results (Benabid et al., 2009). This left little room for surgery as a treatment for PD, and with time it became a forgotten therapy. But as time would show, forgotten, but not lost.

Despite its initial success in treating $\mathrm{PD}$, it was eventually found that levodopa had long-term complications. After 5-7 years of treatment, many patients began to cycle between periods of mobility accompanied by debilitating dyskinesias and periods of severe akinesia (Goetz et al., 2005). This left clinicians searching for other alternatives for patients suffering from end stage PD. There began to be a slow resurgence of ablative surgical therapies, primarily pallidotomy for the treatment of $\mathrm{PD}$ and thalamotomy for the treatment of tremor. Then, in 1987, another serendipitous discovery occurred and once again, opportunity favored the prepared mind. While performing a thalamotomy for tremor and probing for the exact location for lesioning using electrical stimulation, Benabid et al. (1987) discovered that at frequencies higher than $100 \mathrm{~Hz}$, the patient's tremor could be acutely and reversibly modified. In essence, high frequency electrical stimulation of a deep brain nucleus could mimic the effects of lesioning in a reversible and safe manner. This discovery was groundbreaking and led to the resurrection of stereotactic functional neurosurgery in the treatment of movement disorders and the birth of DBS techniques. 
Today, DBS is used to treat a wide variety of conditions. It is not only the primary form of stereotactic functional neurosurgery used to treat movement disorders, which is the focus of this review, but is also used to treat epilepsy and psychiatric disorders such as depression, obsessive compulsive disorder, and Tourette's syndrome as well (Tye et al., 2009). The future indications for DBS will likely only continue to expand as our understanding of neurocircuitry and neuromodulation grows.

\section{DEEP BRAIN STIMULATION NEUROSURGICAL PROCEDURE (TYE ET AL., 2009)}

Current DBS surgical targets for the treatment of movement disorders primarily include placement of an electrode in the subthalamic nucleus (STN), globus pallidus internus (GPi), and ventral intermediate (VIM) thalamus. Although certain details regarding the surgical technique may vary among different institutions, all combine stereotactic technique with detailed image guidance. Stereotaxis is a minimally invasive surgical procedure that makes use of a three-dimensional coordinate system to locate accurately a target in a deep-seated area of the brain and to perform on it some action, such as electrophysiologic monitoring and placement of a stimulating electrode. There are numerous designs for stereotactic devices including: translational systems, arc-centered systems, focal point systems, Polar coordinate systems, burr hole-mounted devices, phantom target systems, computer-based systems, and frameless systems.

Typically, a stereotactic head frame is placed on the patient under local anesthesia in an operating room setting and a computed tomography (CT) scan or, more commonly, a magnetic resonance imaging (MRI) scan, is obtained to identify the anterior commissure, posterior commissure, and the mid-commissural point. Based on the location of these structures, well-established $x, y$, and $z$ target coordinates are used for planning electrode placement based on the patient's pathology and target selected. Commercially available planning software can then be used to determine the target coordinates and an entry point that will allow passage of the electrode through the brain without traversing the ventricle or damaging vascular structures.

After appropriate imaging has been completed and an operative plan formulated, the patient is returned to the operating room, where, under sterile conditions and local anesthesia, surgery commences (Figure 2). A scalp incision and burr hole are placed in the skull at the predetermined entry point. Microelectrode recording is used to verify correct electrode placement in deep brain nuclei. Following the placement of electrodes, test stimulation is conducted using a temporary external stimulator. The patient is kept awake to allow intraoperative evaluation of the therapeutic benefit of DBS. Further, verbal feedback from the awake patient regarding unwanted side effects may also be evaluated. For example, paresthesias with stimulation may indicate current spread into the somatosensory thalamus, or visual phenomena may represent current spread to the optic tract. If such unwanted side effects are noted, the electrode may be moved to another location. This process essentially allows the neurosurgeon to functionally map the patient specific to the patient's own unique anatomy, neurocircuitry, and stimulation threshold. Once the electrode is in place, both intraoperative fluoroscopy and postoperative MRI or

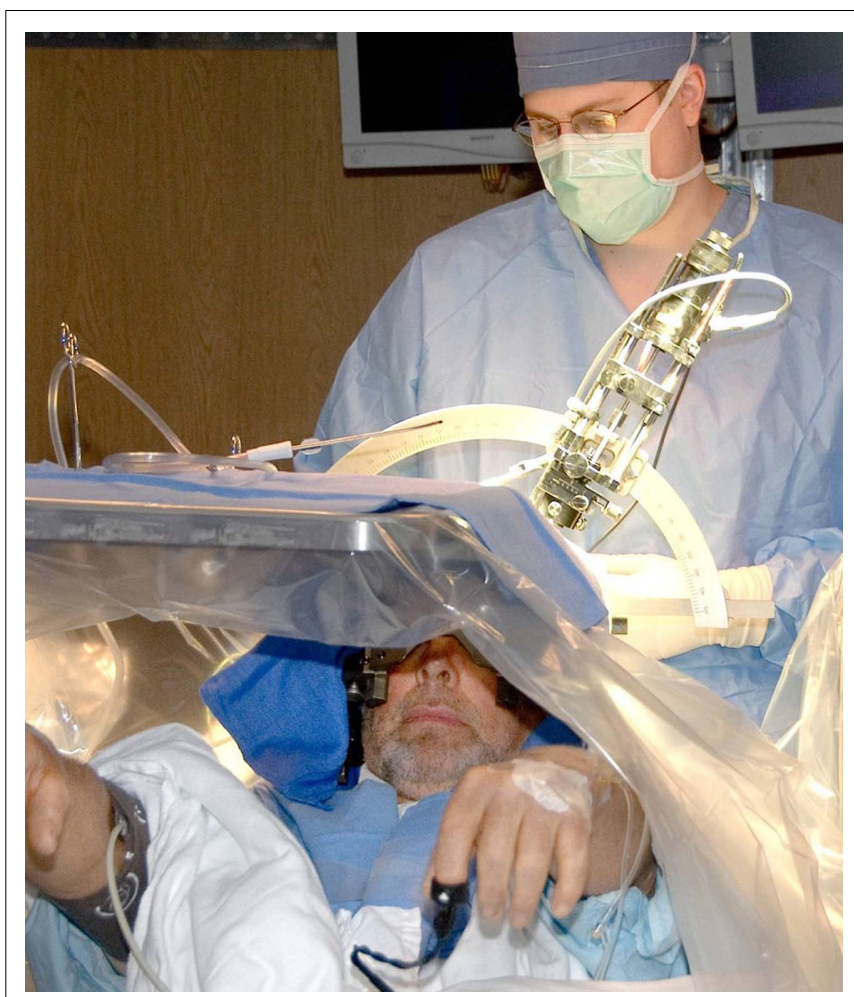

FIGURE 2 | Intraoperative photo of a patient undergoing DBS surgery for Parkinson's disease. As can be seen in the picture, patients are typically kept awake during the surgery to clinically assess the efficacy of electrode placement with real time stimulation, as well as any unwanted side effects. If the location is deemed suboptimal, it can easily be changed intraoperatively and reassessed.

CT are utilized to confirm proper placement (Figure 3). After correct placement is confirmed and trial stimulation is deemed successful, a pulse generator is placed in the subclavicular space, similar to a pacemaker. Stimulation parameters (frequency, amplitude, pulse widths, etc.) vary based on the disorder being treated, patient response, and the presence of side effects.

\section{CLINICAL INDICATIONS}

\section{PARKINSON'S DISEASE}

Parkinson's disease is a chronic progressive neurodegenerative movement disorder affecting the extrapyramidal motor system. The central pathologic substrate of the disease is degeneration of the dopaminergic neurons in the substantia nigra. Clinical hallmarks of the condition classically include bradykinesia, rigidity, and resting tremor (Gelb et al., 1999). PD is estimated to affect approximately 1 million Americans, roughly $1 \%$ of the population over 60 years of age (Nutt and Wooten, 2005). As the population ages, this number will only increase. As this disabling, chronic disease progresses, it leads to a significant loss in the quality of life (Schrag et al., 2000). First line treatment for PD typically includes dopaminergic medications, particularly levodopa. Initially, medical therapy is a very effective treatment, alleviating symptoms and improving the quality of life. However, as the disease progresses it often requires escalating medication doses and 


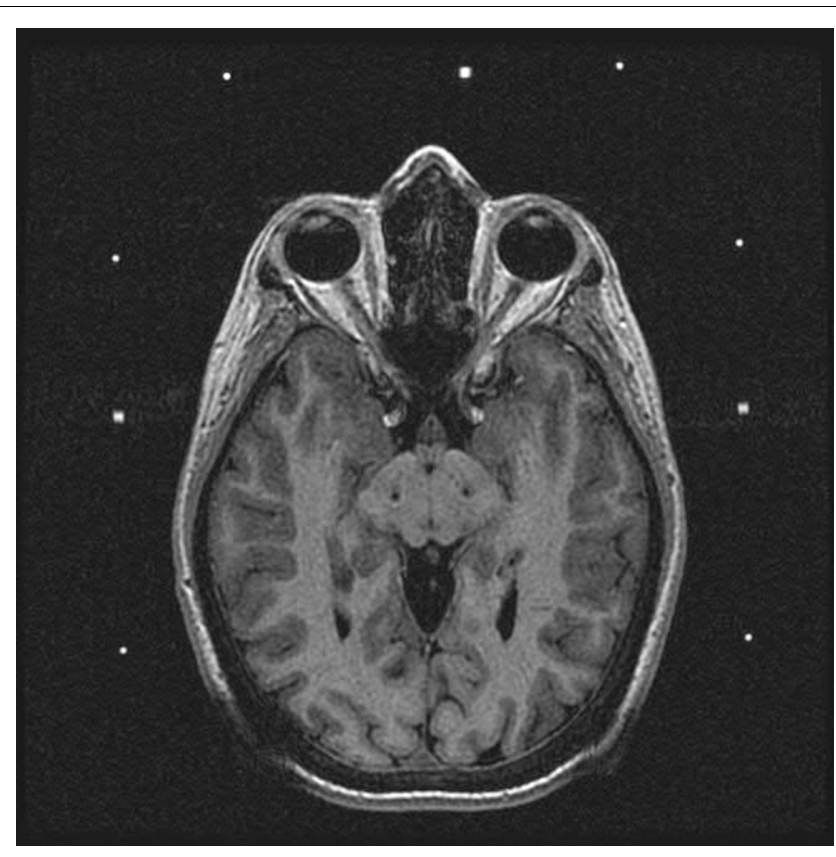

FIGURE 3 | Postoperative MRI demonstrating placement of electrodes in the STN bilaterally for treatment of idiopathic advanced PD.

frequencies to achieve the same treatment effect. This can lead to rapidly cycling motor fluctuations between periods of mobility that may be accompanied by debilitating dyskinesias and periods of severe akinesia (Goetz et al., 2005).

Some of the initial surgical therapies for PD have included irreversible brain lesioning techniques such as thalamotomy and pallidotomy (Cooper and Bravo, 1958; Svennilson et al., 1960; Matsumoto et al., 1976; Cooper, 1977; Ohye et al., 1982; Laitinen et al., 1992). While effective in reducing Parkinsonian symptoms, these therapies often resulted in severe side effects such as dysarthria, disequilibrium, visuospatial impairment, and homonymous hemianopsia, with worse side effects occurring when the procedure was performed bilaterally. Benabid et al. (1987) discovered that high frequency stimulation of the VIM nucleus of the thalamus could mimic the effects of this lesioning, but in a reversible and adjustable manner, thereby reducing the adverse effects secondary to the permanency of brain lesioning. This discovery opened a new world of possibilities for stereotactic functional neurosurgery and DBS.

In their published series, Benabid et al. (1991, 1996) demonstrated that treatment with VIM thalamic DBS provided significant benefit in the treatment of tremor, but not the other symptoms of PD. These studies confirmed the efficacy of DBS; however, due to its limited effects on bradykinesia and rigidity when targeting the thalamus, other neural targets were sought. Given the previous success with pallidotomy in the treatment of $\mathrm{PD}$, the internal segment of the globus pallidus became a natural next target for stimulation (Laitinen et al., 1992). In addition, recent animal models had shown increased glutamatergic output of the STN in induced Parkinsonism (Robledo and Feger, 1990; Parent and Hazrati, 1995). In 1-methyl-4-phenyl-1,2,3,6-tetrahydropyridine
(MPTP) treated primates, Bergman et al. (1990) showed that lesioning of the STN, and Benazzouz et al. (1993) showed that stimulation of the STN, both reduced all of the major symptoms of PD. Thus, both GPi and STN were tried in human patients in the treatment of advanced PD. Other investigated targets include the zona incerta (Plaha et al., 2006), pedunculopontine tegmental nucleus (Stefani et al., 2007; Ferraye et al., 2010), and the centromedian-parafascicular complex of the thalamus (Peppe et al., 2008).

After years of research, the three currently accepted primary targets used for DBS in the treatment of advanced PD refractory to medical therapy are the VIM thalamus, GPi, and the STN (Pollak et al., 2002). Each has associated benefits and risks specific to that target which are critical when considering patient selection (Limousin and Martinez-Torres, 2008).

\section{Thalamus}

Although DBS of the VIM thalamus does not significantly alter bradykinesia or rigidity, it remains an effective target for treatment of certain patients with tremor dominant PD refractory to medical therapy (Benabid et al., 1991; Koller et al., 1997; Tasker, 1998; Limousin et al., 1999; Rehncrona et al., 2003). Initially, thalamic DBS was performed contralateral to thalamotomy to decrease the morbidity associated with bilateral thalamotomy (LimousinDowsey et al., 1999). However, over time many studies have proven VIM thalamic DBS to be a safe and effective treatment alternative that has essentially replaced thalamotomy (Benabid et al., 1991; Koller et al., 1997; Tasker, 1998; Limousin et al., 1999; Rehncrona et al., 2003). Contralateral limb tremor is the most improved symptom with thalamic DBS. Although there are some reports of mild improvement in bradykinesia and rigidity, it is generally felt that these are artifactual and secondary to the improvements in the resting tremor (Limousin-Dowsey et al., 1999; Pollak et al., 2002). Likewise, gait and postural stability do not improve with thalamic DBS (Defebvre et al., 1996; Limousin et al., 1999; Pollak et al., 2002). Despite its main limitation to tremor improvement, however, patients have significant improvement in measures for both quality of life and in performing the functional activities of daily living (ADLs; Koller et al., 1997; Hariz et al., 1998; Woods et al., 2001). Thalamic DBS has been shown to have long-term benefit for tremor control for more than 5 years postoperatively (Rehncrona et al., 2003; Hariz et al., 2007). Furthermore, patients are able to maintain cognitive function after thalamic DBS (Schuurman et al., 2002). However, thalamic DBS does not typically reduce drug dosage, due to its limited effects on other symptoms, and the disease continues to progress despite tremor control (LimousinDowsey et al., 1999; Hariz et al., 2007). Thus, VIM thalamic DBS has fallen out of favor as a preferred target for the general treatment of advanced PD, causing investigators to focus on other targets. In fact, Fraix et al. (2005) have shown significant improvement in all major Parkinsonian symptoms in patients previously treated with thalamic DBS who subsequently underwent STN DBS. Nevertheless, thalamic stimulation remains an option in appropriate advanced PD patients who are either tremor predominant or are not candidates for other targets. Like thalamotomy, thalamic DBS side effects can include dysarthria and worsening balance (Tasker, 1998). While these symptoms can effectively be controlled with 
adjusting the level of stimulation, they should still be weighed carefully in patient selection for this procedure.

\section{Globus pallidus internus}

Deep brain stimulation of the GPi was initially proposed as an alternative to pallidotomy to decrease patient morbidity. This procedure has been performed on patients since 1994. Since then, numerous studies have demonstrated overall significant improvements in patients with advanced PD treated with GPi DBS (Ghika et al., 1998; Volkmann et al., 1998; Kumar et al., 2000; Durif et al., 2002; Loher et al., 2002; Lyons et al., 2002; Rodrigues et al., 2007b). Improvements in both gait and posture have also been shown (Volkmann et al., 1998; Grasso et al., 1999). Furthermore, remarkable motor and non-motor quality of life improvements have both been well documented (Vingerhoets et al., 1999; Rodrigues et al., 2007a). Notably, the most consistent beneficial effect seen from GPi DBS is in the reduction of dyskinesias (Ghika et al., 1998; Volkmann et al., 1998, 2004; Kumar et al., 2000; Durif et al., 2002; Loher et al., 2002; Lyons et al., 2002; Rodrigues et al., 2007b). Many patients with PD who have been treated chronically with levodopa suffer from dyskinesias and motor fluctuations. They cycle between periods of good mobility while taking levodopa ("on" periods) and impaired mobility while off levodopa ("off" periods; Lang and Lozano, 1998). These fluctuations are often refractory to changes in medical therapy and very debilitating. Thus, it is in this population that GPi DBS has been most successful. This is felt to be a direct effect of the high frequency stimulation, as studies demonstrate no significant decrease in levodopa dose reduction postoperatively that could otherwise alter dyskinesias (Limousin and Martinez-Torres, 2008). GPi DBS has also been reported to reduce both the amount and severity of on/off fluctuations (Ghika et al., 1998; Volkmann et al., 1998; Loher et al., 2002; Lyons et al., 2002).

While the benefit in dyskinesia control is relatively universal in the current literature for GPi DBS, there is some variability in other outcome measures. Most studies show no significant difference between preoperative and postoperative "on" period Unified Parkinson's Disease Rating Scale (UPDRS) motor scores over time (Ghika et al., 1998; Kumar et al., 2000; Durif et al., 2002; Volkmann et al., 2004; Rodrigues et al., 2007b). However, there are considerable differences in the magnitude of changes seen between the pre- and postoperative "off" period UPDRS motor scores, as well as differences in the type of off-drug symptoms improved (Ghika et al., 1998; Kumar et al., 2000; Durif et al., 2002; Lyons et al., 2002; Volkmann et al., 2004; Rodrigues et al., 2007b). Some authors postulate that these differences may be explained by the complexity of GPi connections (Bejjani et al., 1997; Krack et al., 1998a; Gross et al., 1999; Limousin and Martinez-Torres, 2008). When different areas of the GPi are stimulated there are different clinical results. Both Bejjani et al. (1997) and Krack et al. (1998a) showed that stimulation of the ventral portion of the globus pallidus resulted in improvement in rigidity and dyskinesias but often times can induce akinesia; on the other hand, stimulation of the dorsal GPi caused improvement in rigidity and akinesia, but induced dyskinesias in a number of patients.

Over time, the reduction of dyskinesias persists for greater than 4-5 years in available long-term studies (DBS Study Group, 2001;
Volkmann et al., 2004). However, some studies show a gradual decrease in the benefit for off medication symptoms over time (DBS Study Group, 2001; Durif et al., 2002; Volkmann et al., 2004). Furthermore, the improvements in ADLs have also been shown to be lost after the first year (Volkmann et al., 2004). The gradual reduction in some of the clinical benefits over time and the complexity of the globus pallidus connections resulting in variable clinical outcomes have caused some clinicians to prefer other DBS targets. Some of the reported side effects related to the target include paresthesias, muscle contractions, visual flashes, worsening akinesia, dysarthria, weight gain, eyelid opening apraxia, confusion, and cognitive decline (Limousin and Martinez-Torres, 2008). Nevertheless, DBS of the globus pallidus has proven to be a safe procedure with low morbidity that can benefit patients with advanced $\mathrm{PD}$, particularly those with severe motor fluctuations.

\section{Subthalamic nucleus}

Deep brain stimulation of the STN has evolved to become the most promising surgical treatment of medically refractory, advanced PD. Studies have consistently shown that DBS of the STN improves bradykinesia, rigidity, tremor, postural control, and gait (Limousin et al., 1995, 1998; Kumar et al., 1998; Moro et al., 1999; Pinter et al., 1999; Houeto et al., 2000; Molinuevo et al., 2000; Herzog et al., 2003; Kleiner-Fisman et al., 2003; Krause et al., 2004b). Off medication motor symptoms seem to improve most significantly, with reported improvements averaging between 40 and $60 \%$ on the standardized UPDRS (Kumar et al., 1998; Limousin et al., 1998; Moro et al., 1999; Pinter et al., 1999; Molinuevo et al., 2000; Kleiner-Fisman et al., 2003; Krause et al., 2004b). The dose of levodopa is also markedly reduced with an associated reduction in levodopa induced dyskinesias (Kumar et al., 1998; Limousin et al., 1998; Moro et al., 1999; Fraix et al., 2000; Houeto et al., 2000; Volkmann et al., 2001; Kleiner-Fisman et al., 2003; Krause et al., 2004b). Molinuevo et al. (2000) have even shown that complete withdrawal of levodopa is feasible with bilateral STN DBS. Multiple studies have also demonstrated significant quality of life improvements in not only those measures related to motor benefits, but also in the mental, emotional, social, cognitive, and communicative aspects of life (Kumar et al., 1998; Lagrange et al., 2002; MartinezMartin et al., 2002; Lezcano et al., 2004; Lyons and Pahwa, 2005). This benefit has been shown to be associated with quality of life improvements in the patient's caregiver as well (Lezcano et al., 2004). There have also been reports of non-motor improvement in constipation, sleep, sensory complaints, bladder symptoms, and urodynamics (Moro et al., 1999; Cicolin et al., 2004; Seif et al., 2004; Winge et al., 2007; Witjas et al., 2007; Zibetti et al., 2007).

In a randomized controlled trial of STN DBS vs. best medical management, DBS was shown to be superior to medical management alone (Deuschl et al., 2006). Deuschl et al. enrolled 156 patients with advanced PD and severe motor symptoms in the study. Primary endpoints included changes in the quality of life as measured by the Parkinson's Disease Questionnaire (PDQ39) and severity of symptoms off medication per the UPDRS-III after 6 months. Neurostimulation resulted in significantly greater improvements in both the quality of life and the severity of motor symptoms. Serious adverse events were more common in the surgical group (including one patient death), but overall adverse 
events were more common in the medication group. In addition to being superior to best medical management alone in advanced PD patients, STN DBS has also been shown to be a cost effective treatment of PD. Fraix et al. conducted a multicenter prospective study of 95 consecutive PD patients treated with bilateral STN DBS. They compared the cost of the disease for a 6-month period before the surgery and a 6-month period after the surgery and found there was a significant decrease in the cost from 10,087 euros before surgery to 1673 euros after surgery $(p<0.0001)$, mainly due to a decrease in the need for medication (Fraix et al., 2006).

Initial criticism of DBS as a therapeutic modality cited a lack of long-term follow up in these patients raising questions about harmful effects of chronic stimulation and whether or not initial benefits were sustained over time. Now, long-term follow up of STN DBS patients is available and shows significantly sustained benefit years after surgery. Krack et al. (2003) found that patients treated with bilateral STN DBS continued to have significant benefit in both off medication motor symptoms and on medication dyskinesias 5 years after surgery. However, while there was no control group in this study, worsening of akinesia, speech, postural stability, freezing of gait, and cognitive function worsened over this period of time consistent with the natural history of the disease. This suggests that while STN DBS can alter symptoms and greatly improve quality of life, it does not alter disease progression. Schupbach et al. (2005) also found that 5 years after surgery there were sustained significant improvements in ADLs and parkinsonian motor disability scores in both the off and on drug states per UPDRS criteria. Furthermore, the severity of levodopa related dyskinesias and daily doses were significantly reduced after 5 years. Once again, moderate motor and cognitive decline was noted over time, which was felt to be due to natural progression of the disease. Wider et al. (2008) found similar results with sustained benefit after 5 years.

Side effects observed after STN DBS include dysarthria, neuropsychiatric problems, cognitive deterioration, eyelid opening apraxia, weight gain, stimulation induced dyskinesias, and worsening akinesia if leads are placed too deeply (Pollak et al., 2002; Limousin and Martinez-Torres, 2008). Cognitive decline has been a closely scrutinized trend after surgery. As noted above, studies showing long-term sustained benefit in parkinsonian symptoms after STN DBS also note progressive motor and cognitive decline over time (Rodriguez-Oroz et al., 2005; Schupbach et al., 2006). Aybeck et al. prospectively investigated the long-term cognitive profile and incidence of dementia in 57 PD patients treated with STN DBS over a 3-year period. They found that the incidence of dementia over this time period was similar to that reported in medically treated patients and was more likely secondary to the natural evolution of the disease rather than a direct effect of STN DBS (Aybek et al., 2007). Another study conducted by Funkiewiez et al. (2004) focused on the cognitive, mood, and behavioral effects of STN DBS and found that only two cognitive variables worsened (category fluency and total score of fluency) and concluded that STN stimulation did not lead to global cognitive decline. Interestingly, in their study depression improved, but apathy and thought disorders worsened.

As with other DBS targets in PD patients, appropriate patient selection is critical for success. Patients felt to be the best candidates for STN DBS typically have relatively young onset of disease, highly levodopa-sensitive PD, and suffer from severe motor complications of long-term dopaminergic treatment (Pollak et al., 2002). Levodopa sensitivity is felt to be one of the best predictors of STN DBS success (Krack et al., 2000; Kleiner-Fisman et al., 2003). Patients with preoperative cognitive decline or dementia are at risk for accelerated worsening after STN DBS (Aybek et al., 2007). Age at the time of surgery has also been found to be a variable to consider. Derost et al. (2007) showed that postoperative quality of life assessments were better in patients less than 65 years of age undergoing STN DBS than those that were older. Ory-Magne et al. (2007) found that there was a significant negative correlation with age and quality of life improvement as measured by the PDQ-39.

\section{GPi vs. STN}

Many studies have been performed on these targets individually; however, there is limited data comparing the two targets together. While a number of studies include groups of patients implanted with electrodes in the GPi as well as other patients with electrodes in the STN, the majority of these are not randomized or blinded (Krack et al., 1998b; DBS Study Group, 2001; Krause et al., 2001; Volkmann et al., 2001; Peppe et al., 2004; Rodriguez-Oroz et al., 2005). Anderson et al. (2005) published a prospective, randomized, blinded study of 10 patients with GPI implants and 10 patients with STN implants for treatment of advanced PD. Outcomes were measured using the UPDRS-III scale assessed at 3, 6, and 12 months postoperatively. After 12 months there was little difference between the groups with a $48 \%$ improvement in the UPDRS-III in the STN group and 39\% improvement in the GPi group. Dyskinesias were reduced by $89 \%$ in the GPi group compared to $62 \%$ in the STN group. Bradykinesia tended to improve more and there was more of a decrease in levodopa dosage with STN stimulation. However, cognitive and behavioral complications were observed only in combination with STN stimulation. In a more recent and larger study, Follett et al. (2010) published a prospective, randomized, multicenter, blinded study in which 299 patients with idiopathic PD were assigned to undergo either GPi (152 patients) or STN (147 patients) stimulation. The primary outcome was the change in motor function based on the UPDRS-III while receiving stimulation but no antiparkinsonian medication. Secondary outcomes included self-reported function, quality of life, neurocognitive function, and adverse events. At 24 months, mean changes in the primary outcome did not differ between the groups. Furthermore, there was no significant difference in self-reported function. Consistent with previous studies, patients with STN stimulation required less dopaminergic medication. The level of depression worsened after STN DBS, but interestingly improved after GPi DBS. There were no significant differences in adverse events. Based on these studies and available data, most clinicians would agree that motor function improves similarly with both STN and GPi stimulation, but non-motor factors need to be considered before choosing a stimulation site.

\section{TREMOR}

\section{Essential tremor}

Essential tremor is the most common movement disorder affecting up to $5.5 \%$ of individuals aged 65 years or older (Louis et al., 
2009). Patients with essential tremor experience rhythmic, involuntary movements with active movement or posture. The arms, head, and voice are the areas of the body most frequently affected (Bain et al., 1994). The cause of essential tremor is unknown, but a strong genetic component is likely given the high frequency of familial occurrence (Busenbark et al., 1996).

In most affected individuals, essential tremor remains a mild disease. However, in some the tremor escalates in severity and results in significant disability (Busenbark et al., 1991). Hand and arm tremor can impair eating, drinking, handwriting, and grooming. Involuntary head shaking may result in embarrassment and social withdrawal. Voice tremor can impair communication. Medication, in particular beta blockers and primidone, often provide significant relief of disabling arm tremor. Botulinum toxin therapy is sometimes useful for head and voice tremors. There remain, however, those severely affected patients in whom medical therapy fails and functional neurosurgery is considered.

In 1955, Cooper introduced surgical therapy of Parkinsonian tremor using targeted lesions in the ventral thalamus (Cooper, 1981). Over time, surgery targeting the ventral lateral (VL) nucleus of the thalamus became the effective lesioning site for essential tremor. Thalamotomy was shown to have marked benefit in essential tremor and was performed predominately unilaterally (Goldman et al., 1992). Bilateral thalamotomy is rarely employed and carries an increased risk of lasting dysarthria (Zirh et al., 1999).

Benabid made the fundamental discovery that continuous high frequency stimulation of the ventral thalamus could alleviate tremor without the risk of permanent side effects (Benabid et al., 1991). Further studies confirmed that DBS had a profound benefit in essential tremor (Hubble et al., 1996; Ondo et al., 1998; Koller et al., 1999; Limousin et al., 1999). These reports led to a direct comparison study of thalamotomy and DBS of the thalamus for treatment of tremors, including essential tremor. This study reported significant tremor suppression in both treatment groups. However, thalamic stimulation resulted in greater reduction in tremor, better functional outcome, and fewer side effects. With these findings thalamic stimulation has become the surgical therapy of choice for medically intractable essential tremor. Long-term follow up is available showing that the benefit from thalamic stimulation is maintained. In 19 patients with essential tremor followed for an average of 6.7 years improvement in upper limb tremor remained marked over the entire period of observation (Sydow et al., 2003). An added benefit of thalamic stimulation is the apparent safety of bilateral procedures (Pahwa et al., 1999; Ondo et al., 2001). Dysarthria remains a frequent complication of bilateral stimulation, however, when dysarthria does occur it is generally mild and reversible (Pahwa et al., 2006).

The usefulness of thalamic stimulation in the treatment of essential head and voice tremor remains unproven. While several small series report improvement with bilateral stimulation, long-term studies in larger groups of patients are needed (Taha et al., 1999; Putzke et al., 2005).

\section{Cerebellar tremor}

Lesions involving the cerebellum and its outflow or inflow tracts can result in tremor. Cerebellar tremor is distinguished by the combination of postural tremor with intention tremor-the worsening of tremor especially at the end of a visually guided movement (Deuschl et al., 1998). When tremor also is visible at rest the term "Holmes" tremor is preferred, although "rubral," "midbrain," or "thalamic" tremors have also been used. Cerebellar tremor can be seen as a result of lesions as diverse as multiple sclerosis, stroke, trauma, cavernous hemangiomas, tumors, or degenerative disease. Over the past decade, DBS has been an emerging therapy for disabling cerebellar tremor of many different etiologies.

\section{Tremor of multiple sclerosis}

The inflammatory lesions of multiple sclerosis frequently affect cerebellar inflow or outflow pathways. These lesions individually or in combination may result in tremor often in combination with ataxia (Feys et al., 2005). In a population-based study tremor was present in $25 \%$ of patients with multiple sclerosis and in $3 \%$ it was severe (Pittock et al., 2004). The severe cerebellar tremor of multiple sclerosis is often disabling and impairs even the most rudimentary functions. Medical and physical therapy is ineffective and surgical therapy is often considered.

Cooper (1960) first reported the use of thalamotomy to alleviate tremor in multiple sclerosis and reported relief of tremor in $80-100 \%$ of patients. However, experience over the subsequent 20 years raised concern. Speelman reported that a reduction in intention tremor could be almost uniformly achieved with thalamotomy, however, improvement in functional status was not demonstrable. In addition the complication rates were high and often included serious events such as limb weakness, dysarthria, or disease relapse (Speelman and Van Manen, 1984).

Given the concerns raised by thalamotomy in multiple sclerosis patients, DBS with its reversible effects seemed to offer advantage. Geny reported that VIM stimulation reduced tremor in $69 \%$ of multiple sclerosis patients. The operation was tolerated without major complications, but functional improvement was minimally improved (Geny et al., 1996). Long-term studies of DBS in multiple sclerosis echo these findings. One year after implantation, patients demonstrated lasting benefit in tremor control (Hooper et al., 2002; Berk et al., 2004). Improvement in feeding activities was found in some but functional capacity was otherwise unchanged.

Thalamic stimulation has been compared to thalamotomy in multiple sclerosis patients. In one study, lesional surgery had a greater degree of suppression of tremor, but stimulation had fewer severe complications (Bittar et al., 2005). In another comparison of 10 patients randomly assigned to thalamotomy or thalamic stimulation there was no difference between the therapies and the effects of both tended to wane at 5 years (Schuurman et al., 2008). A metaanalysis of all available studies addressed this issue and concluded that effective tremor reduction followed both thalamotomy (94\%) and DBS (96\%) and both were associated with significant complications. Both therapies have advantages and disadvantages and these need to be discussed with each patient (Yap et al., 2007). From these studies one can conclude that patients with tremor from multiple sclerosis should be carefully selected before either thalamic DBS or thalamotomy is undertaken. The best candidates would have stable disease and impairment entirely from limb tremor and not from ataxia or weakness. Preoperative counseling is key in preparing the patient for the best result which 
is reduction in tremor with unpredictable and perhaps only mild benefit on limb function (Critchley and Richardson, 1998).

\section{Post-traumatic and post-stroke tremor}

Cerebellar tremor can follow head trauma (Biary et al., 1989). In closed head trauma the responsible lesion has been shown in the dentatothalamic cerebellar outflow pathway and likely result from shear injury (Krauss et al., 1995). Likewise stroke, either infarction or hemorrhage, in these regions can result in a delayed onset cerebellar tremor (Alarcon et al., 2004). When severe these tremors result in persistent disability as medication treatment is not available.

Post-traumatic tremor has been less responsive than other tremors to thalamotomy. In a comparative study moderate to marked improvement in tremor was observed in $86 \%$ of Parkinson's disease patients, $83 \%$ of the patients with essential tremor, $67 \%$ of the patients with various cerebellar tremors, and $50 \%$ of the patients with post-traumatic tremor (Jankovic et al., 1995). Krauss reported a large series of 35 patients with tremor following head injury treated with stereotactic lesions of the ventral thalamus or zona incerta (Krauss et al., 1994). A marked or complete tremor reduction was achieved in 65 and $88 \%$ had some degree of improvement. An incomplete but significant improvement in disability was recorded. A beneficial effect of thalamic stimulation has been reported in individual cases of post-traumatic or poststroke tremor (Broggi et al., 1993; Nguyen and Degos, 1993; Geny et al., 1995).

Recently, dual deep brain stimulator leads were used to span a larger region of the ventral thalamus (VIM, Voa, and Vop) resulting in better control in post-traumatic tremor (Foote and Okun, 2005). The use of multiple targets in DBS provides a possible avenue for improving the results in this and other forms of severe cerebellar tremor (Foote et al., 2006).

\section{Orthostatic tremor}

Orthostatic tremor is a rare syndrome in which high frequency $12-18 \mathrm{~Hz}$ tremor bursts appear immediately upon standing and cause severe postural instability. The tremor may be responsive to pharmacologic agents such as clonazepam or gabapentin. However, many patients fail to respond or become tolerant to these agents.

Recently, case reports of bilateral thalamic stimulation in three patients have demonstrated beneficial effects in treatment resistant orthostatic tremor (Espay et al., 2008; Guridi et al., 2008). These preliminary reports hold promise that DBS may be an effective therapy for this disabling disorder.

\section{DYSTONIA}

Dystonia is a family of movement disorders in which sustained muscle contractions lead to twisting, abnormal posture, relentless muscle spasm, or other unwanted repetitive movements (Fahn et al., 1998). It is the most common type of movement disorder after PD and tremor. There are several ways in which dystonia can be classified. First, it is classified as either primary or secondary dystonia. Primary or idiopathic dystonia occurs in the absence of other neurologic signs and without abnormalities on neuroimaging. Secondary dystonia is due to some identified cause, such as stroke, trauma, drugs (tardive dystonia), or is the result of another neurologic disorder such as Wilson's disease. Dystonia may also be classified based on anatomical distribution and includes generalized, segmental, and focal dystonias. Focal dystonias may include cervical dystonia (spasmodic torticollis), blepharospasm, oculogyric crisis, oromandibular dystonia, spasmodic dysphonia/laryngeal dystonia, and focal hand dystonia (also known as musician's or writer's cramp). The combination of blepharospasmodic contractions and oromandibular dystonia is called cranial dystonia or Meige syndrome. Interestingly, taskrelated factors are sometimes suspected to cause focal dystonia as they may appear in patients who perform high precision movements such as musicians, engineers, and golfers, where the dystonia is termed "yips." Dystonia may also be classified based on patient genotype. Several genes have been linked to hereditary forms of dystonia, with the TOR1A locus (previously DYT1) being the most well known (Ostrem and Starr, 2008).

Although there is currently no cure for dystonia, there are multiple treatment options available. Medical options include treatment with anticholinergics, tetrabenazine, antiepileptics, benzodiazepines, baclofen, and botulinum toxin for focal or segmental dystonias. While many patients benefit from these therapies, many of these treatments fall short and surgical treatments are considered. As with other movement disorders, lesioning techniques comprised early surgical therapies for the treatment of dystonia, namely pallidotomy (Lozano et al., 1997; Vitek et al., 1998; Ford, 2004). Other surgical options include peripheral denervation and intrathecal baclofen pump implantation, depending on the type of dystonia being treated. Due to prior success in treating dystonia with pallidotomy, the GPi became the natural DBS target for dystonia treatment (Benabid et al., 1998; Lozano and Abosch, 2004; Isaias et al., 2009). Surgical criteria for undergoing DBS typically include a firm diagnosis of dystonia, conservative management failure, and significant disability secondary to the condition.

In patients age seven or older, the FDA has approved pallidal DBS for primary dystonia as well as cervical dystonia (also known as spasmodic torticollis). However, the FDA approval of DBS for dystonia is under a special designation called humanitarian device exemption (HDE), meaning that the FDA has given special approval because it recognizes that for rare conditions it would be difficult for a company to scientifically demonstrate effectiveness of their device in the large number of patients that is normally required and as such the use of this device has probable benefit to people that outweighs the risk of injury or illness from its use. Both GPi and STN targets were included in the HDE labeling, but most of the published literature focuses on GPi and will be the focus of this review.

\section{Primary dystonia}

Among the various types of dystonia, primary generalized dystonia is the best studied with regards to DBS treatment. Numerous studies have focused specifically on GPi DBS for the treatment of primary generalized dystonia, both with and without the TOR $1 A$ mutation (Coubes et al., 2000; Bereznai et al., 2002; Katayama et al., 2003; Krauss et al., 2003; Yianni et al., 2003; Krause et al., 2004a; Vidailhet et al., 2005; Diamond et al., 2006; Kupsch et al., 2006; Starr et al., 2006; Alterman et al., 2007; Tisch et al., 2007). 
These have all shown at least some improvement on the BurkeFahn-Marsden Dystonia Rating Scale (BFMDRS), the commonly used standardized scale for primary generalized dystonia, with most showing improvements of $60-70 \%$ on the movement score (Ostrem and Starr, 2008). In a prospective, multicenter, randomized, controlled trial, Vidailhet et al. (2005) studied 22 patients with primary generalized dystonia treated with GPi DBS. Patients were followed 3, 6, and 12 months postoperatively and BFMDRS scores were compared to preoperative scores. The 3-month evaluation included videotaped double-blind evaluations with and without neurostimulation. Patients had a significant mean improvement of $29 \%$ in the BFDRS movement scores while stimulated compared to no stimulation. Furthermore, 12 month scores showed mean improvements of 54\% in the BFMDRS movement score and 44\% in the BFMDRS disability score compared to preoperative baseline. Following this landmark study, Kupsch et al. (2006) studied 40 patients with primary generalized or segmental dystonia treated with GPi DBS randomized to either neurostimulation or sham stimulation for a 3-month period. At 3 months, patients receiving neurostimulation had a significant mean improvement of 39.9 and $38 \%$ in BFMDRS movement and disability scores, respectively, compared to their counterparts receiving sham stimulation, who had respective improvements of 4.9 and $11 \%$.

In addition to short term clinical improvement, more recent studies have shown long-term sustainability of these benefits. Vidailhet et al. (2007) reported their 3 year follow up on the 22 patients previously studied. BFMDRS motor and disability scores observed at 3 years after treatment remained improved compared to preoperative baselines at 58 and 46\%, respectively. Mild long-term improvement in quality of life and attention were also observed. Isaias et al. (2009) reported on 30 consecutive patients with at least 2 years and up to 8 years of follow up after pallidal DBS. Clinical outcome as measured by changes in the BFMDRS in 23 patients were followed for 3 years, 13 for 4 years, 9 for 5 years, 5 for 6 years, 5 for 7 years, and 1 for 8 years after DBS. Overall improvement at 1 year was maintained in all patients at successive yearly examinations, which led the authors to conclude that pallidal DBS is a safe and effective treatment for primary generalized dystonia, with improvement sustained for up to 8 years in one patient (Isaias et al., 2009). Health related quality of life (HRQoL) has also been shown to significantly improve after pallidal DBS. As part of a randomized sham-stimulation controlled trial on pallidal DBS in primary segmental or generalized dystonia, Muller et al. assessed the HRQoL using the SF-36. After the 3-month shamcontrolled phase, significant HRQoL improvements occurred only in the active-stimulation group. The open-label extension phase resulted in a significant improvement in all SF-36 domains following 6 months of neurostimulation. These results demonstrate a favorable impact of DBS on HRQoL in primary dystonia (Mueller et al., 2007).

Complications of GPi DBS for the treatment of dystonia are similar to complications seen for DBS treatment of other disorders, and include hemorrhage, infection, lead fracture, dysarthria, and visual loss. Despite a significant number of studies, there is limited ability to predict which patients will receive the most benefit from pallidal DBS preoperatively (Ostrem and Starr, 2008). Patients with and without the TOR1A mutation have been reported to have similar results (Coubes et al., 2000; Vidailhet et al., 2005; Kupsch et al., 2006). Furthermore, age of onset of the disease has also been ruled out as a predictor of outcome. However, patients that have had the disease for prolonged durations may fare more poorly due to development of secondary fixed contractures (Alterman et al., 2007).

Patients with primary cervical dystonia (spasmodic torticollis) who have failed conservative therapy with botulinum toxin have been reported to gain significant benefit from GPi DBS (Krauss et al., 1999; Bereznai et al., 2002; Goto et al., 2002; Hung et al., 2007; Kiss et al., 2007). In the Canadian multicenter study of DBS for cervical dystonia, Kiss et al. (2007) performed a prospective, single-blind study of bilateral GPi DBS in 10 patients with severe, chronic, medication-resistant cervical dystonia. Outcomes were assessed by two blinded neurologists at 6 and 12 months after treatment using the Toronto Western Spasmodic Torticollis Rating Scale (TWSTRS), the most commonly used rating scale for cervical dystonia. They found significant mean improvements of 44,64 , and $65 \%$ in the TWSTRS severity, disability, and pain subscores, respectively. Long-term sustained benefit has been reported by Hung et al. (2007) in their series of 10 patients and up to 3 years of postoperative follow up. There also reports of improvement in patients with Meige syndrome (primary cranial-cervical dystonia) after GPi DBS (Muta et al., 2001; Bereznai et al., 2002; Foote et al., 2005; Houser and Waltz, 2005; Ostrem et al., 2007).

\section{Secondary dystonia}

Deep brain stimulation appears to work in some patients with secondary dystonia. There have been reports of cases treated with GPi DBS for dystonia secondary to pantothenate kinase-associated neurodegeneration (Castelnau et al., 2005), X-linked dystonia of parkinsonism (Evidente et al., 2007), post-traumatic dystonia (Yianni et al., 2003; Starr et al., 2006), cerebral palsy associated dystonia (Zorzi et al., 2005; Starr et al., 2006), postencephalitic dystonia (Zorzi et al., 2005), and post-stroke dystonia. In general however, these conditions do not respond as consistently or markedly as primary dystonia (Ostrem and Starr, 2008). One reason for the varied response of DBS for patients with secondary dystonia is that secondary dystonia has several different causes including stroke, trauma, infections, metabolic abnormalities, and cerebral palsy. As a result, the brain areas involved in causing the dystonia are also likely to differ. Therefore, DBS in the GPi may not affect the structure(s) that cause the dystonic movements in patients with secondary dystonia. The one likely exception is tardive dystonia (dystonia that is caused by specific drugs called neuroleptics or the gastrointestinal medications metoclopramide and prochlorperazine) where there is growing evidence of significant improvement in dystonic symptoms from DBS that appears to be comparable to the results in primary generalized dystonia (Yianni et al., 2003; Eltahawy et al., 2004; Krause et al., 2004a; Starr et al., 2006; Damier et al., 2007). Damier et al. (2007) performed a prospective, multicenter, double-blind study of 10 patients with medically refractory tardive dyskinesia treated with bilateral GPi DBS. Successful outcome was defined as more than $40 \%$ decrease in the Extrapyramidal Symptoms Rating Scale at 6 months. At the 6-month mark, all 10 patients had a successful outcome based on this measure and there was a mean improvement of $50 \%$ when 
stimulation was applied compared to the absence of stimulation. The authors concluded that although larger studies are needed, GPi DBS does seem to offer a much needed treatment for this patient population.

\section{MECHANISM OF ACTION OF DBS}

While the clinical benefits of DBS, particularly in the treatment of movement disorders, are well-established, the biological mechanisms of action underlying these effects still remain unclear. Three primary hypotheses have been proposed (Hammond et al., 2008; Tye et al., 2009). The first explanation is that high frequency DBS silences stimulated neurons. Because DBS and ablative surgery have similar therapeutic effects, the stimulation-evoked silencing of pathologically hyperactive neurons was initially postulated as the primary mechanism (Benabid et al., 1987, 2000; Bergman et al., 1990). This notion was further supported by early work measuring STN electrophysiology during DBS (Beurrier et al., 2001; Magarinos-Ascone et al., 2002). However, more recent studies have reported the activation of STN output nuclei with high frequency stimulation, suggesting this hypothesis may be overly simplistic (Garcia et al., 2003).

The second general hypothesis is that high frequency stimulation modulates neuronal network activity and neurotransmission. Electrophysiology studies have clearly demonstrated increased activity in target neurons, consistent with axonal activation during DBS (Benazzouz and Hallett, 2000; Hashimoto et al.,
2003; Miocinovic et al., 2006). Pre-clinical studies have also shown neurotransmitter release in various efferent targets during DBS (Windels et al., 2000, 2003). To better understand the regionspecific effects of DBS on neurotransmission, a MRI-compatible device called the wireless instantaneous neurotransmitter concentration system (WINCS) has been developed (Shon et al., 2010a; Van Gompel et al., 2010; Figure 4). This device is capable of monitoring the release of a variety of neurochemicals during DBS using the electroanalytical techniques of fast-scan cyclic voltammetry at a carbon fiber microelectrode (Bledsoe et al., 2009) and fixed potential amperometry (Agnesi et al., 2009) at enzyme-linked biosensors. WINCS has been used to demonstrate dopamine release in the caudate during STN DBS in the intact rat and pig (Shon et al., 2010b), as well as the parkinsonian rat 6-OHDA model (Lee et al., 2006; Shon et al., 2009). Most recently, WINCS has also shown that there is adenosine release in the caudate during DBS in the rat (Shon et al., 2009). Taken together, these studies monitoring neurotransmitter release strongly suggest that DBS may modulate specific neurons that release specific neurotransmitters, thereby affecting these systems in the brain.

The third hypothesis is that high frequency stimulation induces long-term synaptic changes (plasticity). This has been inferred from the often seen delayed time course of therapeutic effects of stimulation. For example, the therapeutic effects of GPi DBS for dystonia may take months to occur despite consistent high
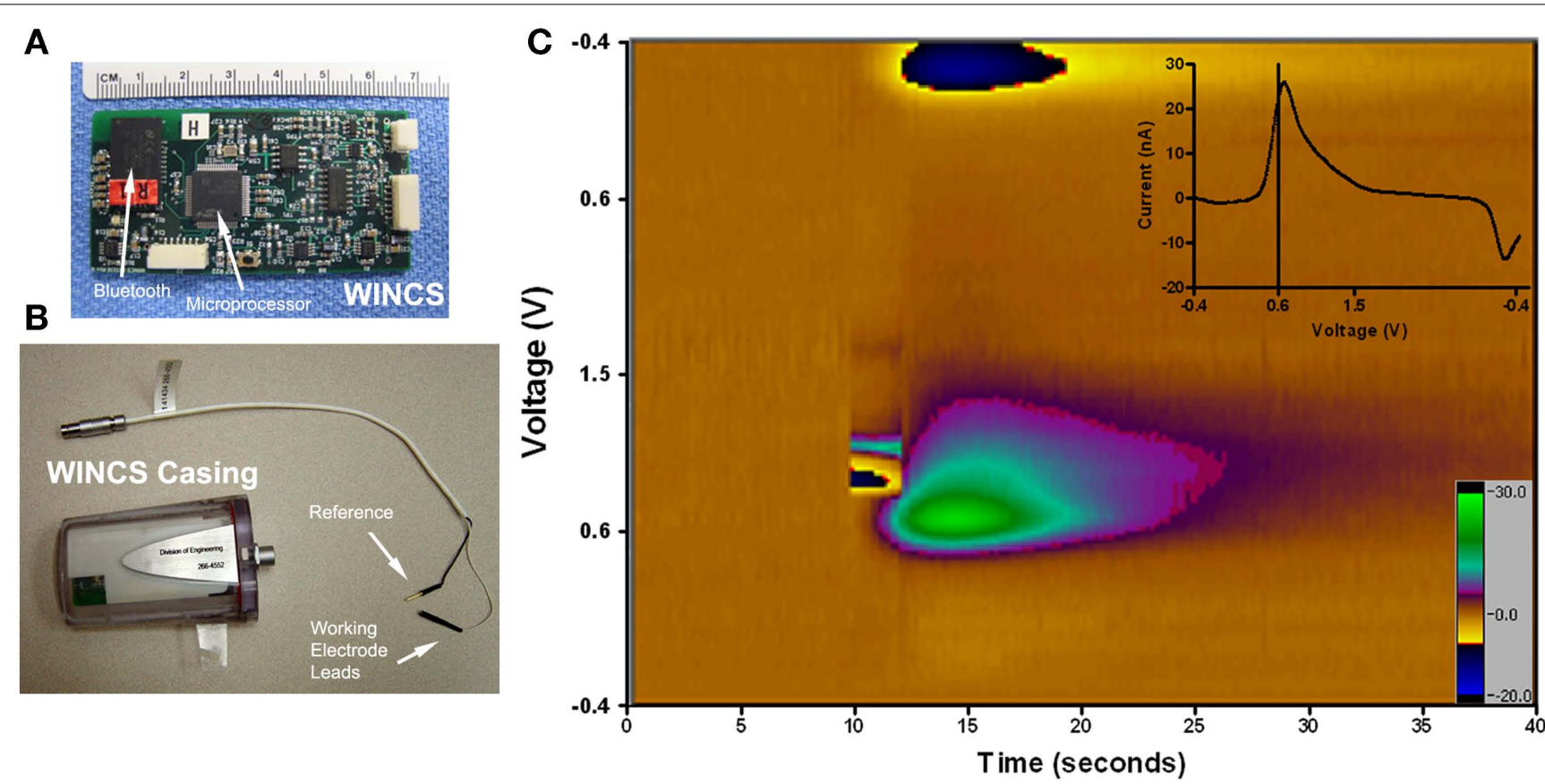

FIGURE 4 | Wireless instantaneous neurotransmitter concentration system (WINCS). (A) Photograph of the WINCS circuit board demonstrating the size, microprocessor, and Bluetooth components. (B) Photograph of WINCS sterilizable casing and the reference and working electrode leads. (C) Pseudocolor plot of stimulated dopamine in a pig with the Medtronic 3389 electrode in the STN and the WINCS carbon fiber in the caudate nucleus. The stimulation parameters are: $3 \mathrm{~mA}, 120 \mathrm{~Hz}, 2 \mathrm{~s}$ stim, $0.5 \mathrm{~ms}$ pulse width. The $y$-axis is the voltage cycled from $-0.4 \mathrm{~V}$ at the top, to $+1.5 \mathrm{~V}$ in the middle, and $-0.4 \mathrm{~V}$ in the bottom; the $x$-axis is time. These scans occur 10 times per second and take 1/100 of a second. The scan parameters are cyclic, -0.4 to +1.5 to $-0.4 \mathrm{~V}$. The current is also recorded in nanoamps and shown by the color bar on the right. Inset at the upper right corner is the unfolded subtracted voltammogram. The oxidation peak is at $+0.6 \mathrm{~V}$ which is typical for dopamine; the downward deflection is the reduction peak. 
frequency stimulation from the early postoperative period, in contrast to the relative early improvement seen in PD patients with DBS (Ostrem et al., 2007).

Clarification of these potential biological mechanisms of action is imperative to help maximize the therapeutic efficacy of DBS and minimize unwanted side effects (Tye et al., 2009). Current and future studies are aimed at further elucidating these mechanisms to expand on and improve this growing therapeutic modality in the treatment of not only movement disorders, but also other neurologic diseases and conditions such as psychiatric disorders. Among the various techniques aimed at better understanding the underlying mechanism of DBS, the field of optogenetics holds particular promise. Optogenetics is a novel technique that combines genetic targeting of specific neurons or proteins with optical technology to control specific events in targeted cells of living organisms (Deisseroth et al., 2006). Neuro-optogenetics utilizes light-gated ion channels that can activate or inhibit neuronal signaling (Banghart et al., 2004; Gunaydin et al., 2010; Toettcher et al., 2011). Gradinaru et al. (2009) utilized this technique to deconstruct the neural circuitry underlying PD in a rat model. They argue that this technique overcomes some of the barriers to understanding the DBS mechanism because it allows very selective sensitization of individual neural circuit components and therefore hypothesis testing for individual cell types without associated complications typically seen from DBS (such as soma-axon decoupling and electrical stimulus artifacts). In their experiment, they systematically stimulated or inhibited various distinct elements of the neural circuit

\section{REFERENCES}

Agnesi, F., Tye, S. J., Bledsoe, J. M., Griessenauer, C. J., Kimble, C. J., Sieck, G. C., Bennet, K. E., Garris, P. A., Blaha, C. D., and Lee, K. H. (2009). Wireless instantaneous neurotransmitter concentration systembased amperometric detection of dopamine, adenosine, and glutamate for intraoperative neurochemical monitoring. J. Neurosurg. 111, 701-711.

Alarcon, F., Zijlmans, J. C., Duenas, G., and Cevallos, N. (2004). Poststroke movement disorders: report of 56 patients. J. Neurol. Neurosurg. Psychiatr. 75, 1568-1574.

Alterman, R. L., Miravite, J., Weisz, D., Shils, J. L., Bressman, S. B., and Tagliati, M. (2007). Sixty hertz pallidal deep brain stimulation for primary torsion dystonia. Neurology 69 , 681-688.

Anderson, V. C., Burchiel, K. J., Hogarth, P., Favre, J., and Hammerstad, J. P. (2005). Pallidal vs subthalamic nucleus deep brain stimulation in Parkinson disease. Arch. Neurol. 62, 554-560.

Aybek, S., Gronchi-Perrin, A., Berney, A., Chiuve, S. C., Villemure, J. G., Burkhard, P. R., and Vingerhoets, F. J. (2007). Long-term cognitive profile and incidence of dementia after STN-DBS in Parkinson's disease. Mov. Disord. 22, 974-981.

Bain, P. G., Findley, L. J., Thompson, P. D., Gresty, M. A., Rothwell, J. C., Harding, A. E., and Marsden, C. D. (1994). A study of hereditary essential tremor. Brain 117(Pt 4), 805-824.

Banghart, M., Borges, K., Isacoff, E., Trauner, D., and Kramer, R. H. (2004). Light-activated ion channels for remote control of neuronal firing. Nat. Neurosci. 7, 1381-1386.

Bejjani, B., Damier, P., Arnulf, I., Bonnet, A. M., Vidailhet, M., Dormont, D., Pidoux, B., Cornu, P., Marsault, C., and Agid, Y. (1997). Pallidal stimulation for Parkinson's disease. Two targets? Neurology 49, 1564-1569.

Benabid, A. L., Benazzouz, A., Hoffmann, D., Limousin, P., Krack, P., and Pollak, P. (1998). Long-term electrical inhibition of deep brain targets in movement disorders. Mov. Disord. 13(Suppl. 3), 119-125.

Benabid, A. L., Chabardes, S., Torres, N., Pollak, P. (2009). Functional neurosurgery for movement disorders: a historical perspective. Prog. Brain Res. 175, 379-391.

Benabid, A. L., Krack, P. P., Benazzouz, A., Limousin, P., Koudsie, A., and Piallat, B., Krack, P., Fraix, V., and

associated with PD and found that direct selective stimulation of the afferent axons to the STN could mimic the therapeutic effects of DBS of the STN in their rat model. Interestingly, they also found that optically induced high frequency stimulation of the layer $\mathrm{V}$ motor cortex projections to the STN resulted in similar effects. Experiments and techniques such as these likely hold the keys to unlocking our understanding of the underlying mechanisms of DBS.

\section{SUMMARY}

Deep brain stimulation is a highly effective, safe, and reversible surgical treatment for advanced PD, tremor, and dystonia. Each of these disorders has obvious differences, but also has striking similarities with regards to symptoms, DBS target, stimulation parameters, and clinical effects. While this field has grown exponentially in the last 20 years, a better understanding of the intricate neurocircuitry associated with these disorders, as well as how DBS can produce such amazing therapeutic benefits, will unlock the door to even more possibilities.

\section{ACKNOWLEDGMENTS}

The authors would like to thank Jamie Van Gompel, M.D. and David Daniels, M.D., Ph.D. for their assistance in creating the figures for this paper. This work was supported by NIH (K08 NS 52232 award) and Mayo Foundation (2008-2010 Research Early Career Development Award for Clinician Scientists) to Kendall H. Lee.

Pollak, P. (2000). Deep brain stimulation of the subthalamic nucleus for Parkinson's disease: methodologic aspects and clinical criteria. Neurology 55, S40-S44.

Benabid, A. L., Pollak, P., Gao, D., Hoffmann, D., Limousin, P., Gay, E. Payen, I., and Benazzouz, A. (1996). Chronic electrical stimulation of the ventralis intermedius nucleus of the thalamus as a treatment of movement disorders. J. Neurosurg. 84, 203-214.

Benabid, A. L., Pollak, P., Gervason, C., Hoffmann, D., Gao, D. M., Hommel, M., Perret, J. E., and De Rougemont, J. (1991). Long-term suppression of tremor by chronic stimulation of the ventral intermediate thalamic nucleus. Lancet 337, 403-406.

Benabid, A. L., Pollak, P., Louveau, A., Henry, S., and De Rougemont, J. (1987). Combined (thalamotomy and stimulation) stereotactic surgery of the VIM thalamic nucleus for bilateral Parkinson disease. Appl. Neurophysiol. 50, 344-346.

Benazzouz, A., Gross, C., Feger, J., Boraud, T., and Bioulac, B. (1993). Reversal of rigidity and improvement in motor performance by subthalamic high-frequency stimulation in MPTP-treated monkeys. Eur. J. Neurosci. 5, 382-389.
Benazzouz, A., and Hallett, M. (2000). Mechanism of action of deep brain stimulation. Neurology 55, S13-S16.

Bereznai, B., Steude, U., Seelos, K., and Botzel, K. (2002). Chronic highfrequency globus pallidus internus stimulation in different types of dystonia: a clinical, video, and MRI report of six patients presenting with segmental, cervical, and generalized dystonia. Mov. Disord. 17, 138-144.

Bergman, H., Wichmann, T., and Delong, M. R. (1990). Reversal of experimental parkinsonism by lesions of the subthalamic nucleus. Science 249, 1436-1438.

Berk, C., Carr, J., Sinden, M., Martzke, J., and Honey, C. R. (2004). Assessing tremor reduction and quality of life following thalamic deep brain stimulation for the treatment of tremor in multiple sclerosis. J. Neurol. Neurosurg. Psychiatr. 75, 1210; author reply $1210-1211$.

Beurrier, C., Bioulac, B., Audin, J., and Hammond, C. (2001). Highfrequency stimulation produces a transient blockade of voltage-gated currents in subthalamic neurons. J. Neurophysiol. 85, 1351-1356.

Biary, N., Cleeves, L., Findley, L., and Koller, W. (1989). Post-traumatic tremor. Neurology 39, 103-106. 
Bittar, R. G., Hyam, J., Nandi, D., Wang, S., Liu, X., Joint, C., Bain, P. G., Gregory, R., Stein, J., and Aziz, T. Z. (2005). Thalamotomy versus thalamic stimulation for multiple sclerosis tremor. J. Clin. Neurosci. 12, 638-642.

Bledsoe, J. M., Kimble, C. J., Covey, D. P., Blaha, C. D., Agnesi, F., Mohseni, P., Whitlock, S., Johnson, D. M., Horne, A., Bennet, K. E., Lee, K. H., and Garris, P. A. (2009). Development of the wireless instantaneous neurotransmitter concentration system for intraoperative neurochemical monitoring using fast-scan cyclic voltammetry. J. Neurosurg. 111, 712-723.

Broggi, G., Brock, S., Franzini, A., and Geminiani, G. (1993). A case of posttraumatic tremor treated by chronic stimulation of the thalamus. Mov. Disord. 8, 206-208.

Bucy, P. (1942). Cortical extirpation in the treatment of involuntary movements. Am. J. Surg. 21, 551-595.

Busenbark, K., Barnes, P., Lyons, K., Ince, D., Villagra, F., and Koller, W. C. (1996). Accuracy of reported family histories of essential tremor. Neurology 47, 264-265.

Busenbark, K. L., Nash, J., Nash, S., Hubble, J. P., and Koller, W. C. (1991). Is essential tremor benign? Neurology 41, 1982-1983.

Carlsson, A., Lindqvist, M., and Magnusson, T. (1957). 3,4Dihydroxyphenylalanine and 5-hydroxytryptophan as reserpine antagonists. Nature 180, 1200.

Castelnau, P., Cif, L., Valente, E. M., Vayssiere, N., Hemm, S., Gannau, A., Digiorgio, A., and Coubes, P. (2005). Pallidal stimulation improves pantothenate kinase-associated neurodegeneration. Ann. Neurol. 57, 738-741.

Cicolin, A., Lopiano, L., Zibetti, M., Torre, E., Tavella, A., Guastamacchia, G., Terreni, A., Makrydakis, G., Fattori, E., Lanotte, M. M., Bergamasco, B., and Mutani, R. (2004). Effects of deep brain stimulation of the subthalamic nucleus on sleep architecture in Parkinsonian patients. Sleep Med. 5, 207-210.

Cooper, I. S. (1953). Ligation of the anterior choroidal artery for involuntary movements; parkinsonism. Psychiatr. Q. 27, 317-319.

Cooper, I. S. (1960). Neurosurgical alleviation of intention tremor of multiple sclerosis and cerebellar disease. N. Engl. J. Med. 263, 441-444.

Cooper, I. S. (1977). Neurosurgical treatment of the dyskinesias. Clin. Neurosurg. 24, 367-390.

Cooper, I. S. (1981). Twenty-five years of experience with physiological neurosurgery. Neurosurgery 9, 190-200.
Cooper, I. S., and Bravo, G. (1958). Chemopallidectomy and chemothalamectomy. J. Neurosurg. 15, 244-250.

Cotzias, G. C., Van Woert, M. H., and Schiffer, L. M. (1967). Aromatic amino acids and modification of parkinsonism. N. Engl. J. Med. 276, 374-379.

Coubes, P., Roubertie, A., Vayssiere, N., Hemm, S., and Echenne, B. (2000). Treatment of DYT1-generalised dystonia by stimulation of the internal globus pallidus. Lancet 355, 2220-2221.

Critchley, G. R., and Richardson, P. L. (1998). Vim thalamotomy for the relief of the intention tremor of multiple sclerosis. Br. J. Neurosurg. 12, 559-562.

Damier, P., Thobois, S., Witjas, T., Cuny, E., Derost, P., Raoul, S., Mertens, P., Peragut, J. C., Lemaire, J. J., Burbaud, P., Nguyen, J. M., Llorca, P. M., and Rascol, O. (2007). Bilateral deep brain stimulation of the globus pallidus to treat tardive dyskinesia. Arch. Gen. Psychiatry 64, 170-176.

Das, K., Benzil, D. L., Rovit, R. L., Murali, R., and Couldwell, W. T. (1998). Irving S. Cooper (1922-1985): a pioneer in functional neurosurgery. $J$. Neurosurg. 89, 865-873.

DBS Study Group. (2001). Deepbrain stimulation of the subthalamic nucleus or the pars interna of the globus pallidus in Parkinson's disease. N. Engl. J. Med. 345, 956-963.

Defebvre, L., Blatt, J. L., Blond, S., Bourriez, J. L., Gieu, J. D., and Destee, A. (1996). Effect of thalamic stimulation on gait in Parkinson disease. Arch. Neurol. 53, 898-903.

Deisseroth, K., Feng, G., Majewska, A. K., Miesenbock, G., Ting, A., and Schnitzer, M. J. (2006). Next-generation optical technologies for illuminating genetically targeted brain circuits. J. Neurosci. 26, 10380-10386.

Derost, P. P., Ouchchane, L., Morand, D., Ulla, M., Llorca, P. M., Barget, M., Debilly, B., Lemaire, J. J., and Durif, F. (2007). Is DBS-STN appropriate to treat severe Parkinson disease in an elderly population? Neurology 68, 1345-1355.

Deuschl, G., Bain, P., and Brin, M. (1998). Consensus statement of the movement disorder society on tremor. Ad hoc Scientific Committee. Mov. Disord. 13(Suppl. 3), 2-23.

Deuschl, G., Schade-Brittinger, C., Krack, P., Volkmann, J., Schafer, H., Botzel, K., Daniels, C., Deutschlander, A., Dillmann, U., Eisner, W., Gruber, D., Hamel, W., Herzog, J., Hilker, R., Klebe, S., Kloss,
M., Koy, J., Krause, M., Kupsch, A. Lorenz, D., Lorenzl, S., Mehdorn, H. M., Moringlane, J. R., Oertel, W., Pinsker, M. O., Reichmann, H., Reuss, A., Schneider, G. H., Schnitzler, A., Steude, U., Sturm, V., Timmermann, L., Tronnier, V., Trottenberg, T., Wojtecki, L., Wolf, E., Poewe, W., and Voges, J. (2006). A randomized trial of deep-brain stimulation for Parkinson's disease. N. Engl. J. Med. 355, 896-908.

Diamond, A., Shahed, J., Azher, S., DatVuong, K., and Jankovic, J. (2006) Globus pallidus deep brain stimulation in dystonia. Mov. Disord. 21, 692-695.

Durif, F., Lemaire, J. J., Debilly, B. and Dordain, G. (2002). Longterm follow-up of globus pallidus chronic stimulation in advanced Parkinson's disease. Mov. Disord. 17, 803-807.

Ehringer, H., and Hornykiewicz, O. (1960). Distribution of noradrenaline and dopamine (3-hydroxytyramine) in the human brain and their behavior in diseases of the extrapyramidal system. Klin. Wochenschr. 38, 1236-1239.

Eltahawy, H. A., Saint-Cyr, J., Giladi, N., Lang, A. E., and Lozano, A. M. (2004). Primary dystonia is more responsive than secondary dystonia to pallidal interventions: outcome after pallidotomy or pallidal deep brain stimulation. Neurosurgery 54, 613-619; discussion 619-621.

Espay, A. J., Duker, A. P., Chen, R., Okun, M. S., Barrett, E. T., Devoto, J., Zeilman, P., Gartner, M., Burton, N., Miranda, H. A., Mandybur, G. T., Zesiewicz, T. A., Foote, K. D., and Revilla, F. J. (2008). Deep brain stimulation of the ventral intermediate nucleus of the thalamus in medically refractory orthostatic tremor: preliminary observations. Mov. Disord. 23, 2357-2362.

Evidente, V. G., Lyons, M. K., Wheeler M., Hillman, R., Helepolelei, L., Beynen, F., Nolte, D., Muller, U. and Starr, P. A. (2007). First case of X-linked dystonia-parkinsonism ("Lubag") to demonstrate a response to bilateral pallidal stimulation. Mov. Disord. 22, 1790-1793.

Fahn, S., Bressman, S. B., and Marsden, C. D. (1998). Classification of dystonia. Adv. Neurol. 78, 1-10.

Ferraye, M. U., Debu, B., Fraix, V., Goetz L., Ardouin, C., Yelnik, J., HenryLagrange, C., Seigneuret, E., Piallat, B., Krack, P., Le Bas, J. F., Benabid A. L., Chabardes, S., and Pollak, P. (2010). Effects of pedunculopontine nucleus area stimulation on gait disorders in Parkinson's disease. Brain 133, 205-214.
Feys, P., Maes, F., Nuttin, B., Helsen, W., Malfait, V., Nagels, G., Lavrysen, A., and Liu, X. (2005). Relationship between multiple sclerosis intention tremor severity and lesion load in the brainstem. Neuroreport 16, 1379-1382.

Follett, K. A., Weaver, F. M., Stern, M., Hur, K., Harris, C. L., Luo, P., Marks, W. J. Jr., Rothlind, J., Sagher, O., Moy, C., Pahwa, R., Burchiel, K., Hogarth, P., Lai, E. C., Duda, J. E., Holloway, K., Samii, A., Horn, S., Bronstein, J. M., Stoner, G., Starr, P. A., Simpson, R., Baltuch, G., De Salles, A., Huang, G. D., and Reda, D. J. (2010). Pallidal versus subthalamic deep-brain stimulation for Parkinson's disease. N. Engl. J. Med. 362, 2077-2091.

Foote, K. D., and Okun, M. S. (2005). Ventralis intermedius plus ventralis oralis anterior and posterior deep brain stimulation for posttraumatic Holmes tremor: two leads may be better than one: technical note. Neurosurgery 56, E445; discussion E445.

Foote, K. D., Sanchez, J. C., and Okun, M.S. (2005). Staged deep brain stimulation for refractory craniofacial dystonia with blepharospasm: case report and physiology. Neurosurgery 56, E415; discussion E415.

Foote, K. D., Seignourel, P., Fernandez, H. H., Romrell, J., Whidden, E., Jacobson, C., Rodriguez, R. L., and Okun, M. S. (2006). Dual electrode thalamic deep brain stimulation for the treatment of posttraumatic and multiple sclerosis tremor. Neurosurgery 58, ONS-280-285; discussion ONS-285-286.

Ford, B. (2004). Pallidotomy for generalized dystonia. Adv. Neurol. 94, 287-299.

Fraix, V., Houeto, J. L., Lagrange, C., Le Pen, C., Krystkowiak, P., Guehl, D., Ardouin, C., Welter, M. L., Maurel, F., Defebvre, L., Rougier, A., Benabid, A. L., Mesnage, V., Ligier, M., Blond, S., Burbaud, P., Bioulac, B., Destee, A. Cornu, P., and Pollak, P. (2006). Clinical and economic results of bilateral subthalamic nucleus stimulation in Parkinson's disease. J. Neurol. Neurosurg. Psychiatr. 77, 443-449.

Fraix, V., Pollak, P., Moro, E., Chabardes, S., Xie, J., Ardouin, C., and Benabid, A. L. (2005). Subthalamic nucleus stimulation in tremor dominant parkinsonian patients with previous thalamic surgery. J. Neurol. Neurosurg. Psychiatr. 76, 246-248.

Fraix, V., Pollak, P., Van Blercom, N., Xie, J., Krack, P., Koudsie, A., and Benabid, A. L. (2000). Effect of subthalamic nucleus stimulation on levodopa-induced dyskinesia in Parkinson's disease. Neurology 55, 1921-1923. 
Funkiewiez, A., Ardouin, C., Caputo, E., Krack, P., Fraix, V., Klinger, H., Chabardes, S., Foote, K., Benabid, A. L., and Pollak, P. (2004). Long term effects of bilateral subthalamic nucleus stimulation on cognitive function, mood, and behaviour in Parkinson's disease. J. Neurol. Neurosurg. Psychiatr. 75, 834-839.

Garcia, L., Audin, J., D’Alessandro, G., Bioulac, B., and Hammond, C. (2003). Dual effect of highfrequency stimulation on subthalamic neuron activity. J. Neurosci. 23, 8743-8751.

Gelb, D. J., Oliver, E., and Gilman, S. (1999). Diagnostic criteria for Parkinson disease. Arch. Neurol. 56, 33-39.

Geny, C., N'Guyen, J. P., Cesaro, P., Goujon, C., Brugieres, P., and Degos, J. D. (1995). Thalamic stimulation for severe action tremor after lesion of the superior cerebellar peduncle. J. Neurol. Neurosurg. Psychiatr. 59, 641-642.

Geny, C., Nguyen, J. P., Pollin, B., Feve, A., Ricolfi, F., Cesaro, P., and Degos, J. D. (1996). Improvement of severe postural cerebellar tremor in multiple sclerosis by chronic thalamic stimulation. Mov. Disord. 11, 489-494.

Ghika, J., Villemure, J. G., Fankhauser, H., Favre, J., Assal, G., and GhikaSchmid, F. (1998). Efficiency and safety of bilateral contemporaneous pallidal stimulation (deep brain stimulation) in levodopa-responsive patients with Parkinson's disease with severe motor fluctuations: a 2year follow-up review. J. Neurosurg. 89, 713-718.

Goetz, C. G., Poewe, W., Rascol, O., and Sampaio, C. (2005). Evidence-based medical review update: pharmacological and surgical treatments of Parkinson's disease: 2001 to 2004. Mov. Disord. 20, 523-539.

Goldman, M. S., Ahlskog, J. E., and Kelly, P. J. (1992). The symptomatic and functional outcome of stereotactic thalamotomy for medically intractable essential tremor. $J$. Neurosurg. 76, 924-928.

Goto, S., Mita, S., and Ushio, Y. (2002). Bilateral pallidal stimulation for cervical dystonia. An optimal paradigm from our experiences. Stereotact. Funct. Neurosurg. 79, 221-227.

Gradinaru, V., Mogri, M., Thompson, K. R., Henderson, J. M., and Deisseroth, K. (2009). Optical deconstruction of parkinsonian neural circuitry. Science 324, 354-359.

Grasso, R., Peppe, A., Stratta, F., Angelini, D., Zago, M., Stanzione, P., and Lacquaniti, F. (1999). Basal ganglia and gait control: apomorphine administration and internal pallidum stimulation in Parkinson's disease. Exp. Brain Res. 126, 139-148.

Greene, P. (2005). Deep-brain stimulation for generalized dystonia. $N$. Engl. J. Med. 352, 498-500.

Gross, R. E., Lombardi, W. J., Hutchison, W. D., Narula, S., Saint-Cyr, J. A., Dostrovsky, J. O., Tasker, R. R., Lang, A. E., and Lozano, A. M. (1999). Variability in lesion location after microelectrode-guided pallidotomy for Parkinson's disease: anatomical, physiological, and technical factors that determine lesion distribution. J. Neurosurg. 90, 468-477.

Gunaydin, L. A., Yizhar, O., Berndt, A., Sohal, V. S., Deisseroth, K., and Hegemann, P. (2010). Ultrafast optogenetic control. Nat. Neurosci. 13, 387-392.

Guridi, J., Rodriguez-Oroz, M. C., Arbizu, J., Alegre, M., Prieto, E., Landecho, I., Manrique, M., Artieda, J., and Obeso, J. A. (2008). Successful thalamic deep brain stimulation for orthostatic tremor. Mov. Disord. 23, 1808-1811.

Hammond, C., Ammari, R., Bioulac, B. and Garcia, L. (2008). Latest view on the mechanism of action of deep brain stimulation. Mov. Disord. 23, 2111-2121.

Hariz, G. M., Bergenheim, A. T., Hariz, M. I., and Lindberg, M. (1998). Assessment of ability/disability in patients treated with chronic thalamic stimulation for tremor. Mov. Disord. 13, 78-83.

Hariz, M. I., Krack, P., Alesch, F., Augustinsson, L. E., Bosch, A., Ekberg, R., Johansson, F., Johnels, B., Meyerson, B., Nguyen, J. P., Pinter, M., Pollak, P. R., Von Raison, F., Rehncrona, S., Speelman, J. D., Sydow, O., and Benabid, A. L. (2007). Multicentre European study of thalamic stimulation for Parkinsonian tremor; a 6-year follow-up. J. Neurol. Neurosurg. Psychiatr. 79, 694-699.

Hashimoto, T., Elder, C. M., Okun, M. S., Patrick, S. K., and Vitek, J. L. (2003). Stimulation of the subthalamic nucleus changes the firing pattern of pallidal neurons. J. Neurosci. 23, 1916-1923.

Hauser, R. A. (2009). New considerations in the medical management of early Parkinson's disease: impact of recent clinical trials on treatment strategy. Parkinsonism Relat. Disord. 15(Suppl. 3), S17-S21.

Herzog, J., Volkmann, J., Krack, P., Kopper, F., Potter, M., Lorenz, D., Steinbach, M., Klebe, S., Hamel, W., Schrader, B., Weinert, D., Muller, D., Mehdorn, H. M., and Deuschl, G.
(2003). Two-year follow-up of subthalamic deep brain stimulation in Parkinson's disease. Mov. Disord. 18 1332-1337.

Hooper, J., Taylor, R., Pentland, B., and Whittle, I. R. (2002). A prospective study of thalamic deep brain stimulation for the treatment of movement disorders in multiple sclerosis. Br. J. Neurosurg. 16, 102-109.

Houeto, J. L., Damier, P., Bejjani, P. B. Staedler, C., Bonnet, A. M., Arnulf, I., Pidoux, B., Dormont, D., Cornu, P., and Agid, Y. (2000). Subthalamic stimulation in Parkinson disease: a multidisciplinary approach. Arch. Neurol. 57, 461-465.

Houser, M., and Waltz, T. (2005). Meige syndrome and pallidal deep brain stimulation. Mov. Disord. 20, 1203-1205.

Hubble, J. P., Busenbark, K. L., Wilkinson, S., Penn, R. D., Lyons, K., and Koller, W. C. (1996). Deep brain stimulation for essential tremor. Neurology 46, 1150-1153.

Hung, S. W., Hamani, C., Lozano, A. M., Poon, Y. Y., Piboolnurak, P., Miyasaki, J. M., Lang, A. E., Dostrovsky, J. O., Hutchison, W. D., and Moro, E. (2007). Long-term outcome of bilateral pallidal deep brain stimulation for primary cervical dystonia. Neurology 68, 457-459.

Isaias, I. U., Alterman, R. L., and Tagliati, M. (2009). Deep brain stimulation for primary generalized dystonia: long-term outcomes. Arch. Neurol. 66, 465-470.

Jankovic, J., Cardoso, F., Grossman, R. G., and Hamilton, W. J. (1995). Outcome after stereotactic thalamotomy for parkinsonian, essential, and other types of tremor. Neurosurgery 37, 680-686; discussion 686-687.

Katayama, Y., Fukaya, C., Kobayashi, K., Oshima, H., and Yamamoto, T. (2003). Chronic stimulation of the globus pallidus internus for control of primary generalized dystonia. Acta Neurochir. Suppl. 87, 125-128.

Kiss, Z. H., Doig-Beyaert, K., Eliasziw, M., Tsui, J., Haffenden, A., and Suchowersky, O. (2007). The Canadian multicentre study of deep brain stimulation for cervical dystonia. Brain 130, 2879-2886.

Kleiner-Fisman, G., Fisman, D. N., Sime, E., Saint-Cyr, J. A., Lozano, A. M., and Lang, A. E. (2003). Longterm follow up of bilateral deep brain stimulation of the subthalamic nucleus in patients with advanced Parkinson disease. J. Neurosurg. 99, 489-495.

Klemme, R. (1940). Surgical treatment of dystonia, paralysis agitans and athetosis. Arch. Neurol. Psychiatry 44, 926.
Koller, W., Pahwa, R., Busenbark, K., Hubble, J., Wilkinson, S., Lang, A., Tuite, P., Sime, E., Lazano, A., Hauser, R., Malapira, T., Smith, D., Tarsy, D., Miyawaki, E., Norregaard, T. Kormos, T., and Olanow, C. W. (1997). High-frequency unilateral thalamic stimulation in the treatment of essential and parkinsonian tremor. Ann. Neurol. 42, 292-299.

Koller, W. C., Lyons, K. E., Wilkinson, S. B., and Pahwa, R. (1999). Efficacy of unilateral deep brain stimulation of the VIM nucleus of the thalamus for essential head tremor. Mov. Disord. 14, 847-850.

Koller, W. C., Pahwa, P. R., Lyons, K. E., and Wilkinson, S. B. (2000). Deep brain stimulation of the Vim nucleus of the thalamus for the treatment of tremor. Neurology 55, S29-S33.

Krack, P., Batir, A., Van Blercom, N. Chabardes, S., Fraix, V., Ardouin, C., Koudsie, A., Limousin, P. D., Benazzouz, A., Lebas, J. F., Benabid, A. L., and Pollak, P. (2003). Five-year follow-up of bilateral stimulation of the subthalamic nucleus in advanced Parkinson's disease. N. Engl. J. Med. 349, 1925-1934.

Krack, P., Dowsey, P. L., Benabid, A. L., Acarin, N., Benazzouz, A., Kunig, G., Leenders, K. L., Obeso, J. A., and Pollak, P. (2000). Ineffective subthalamic nucleus stimulation in levodopa-resistant postischemic parkinsonism. Neurology 54, 2182-2184.

Krack, P., Fraix, V., Mendes, A., Benabid, A. L., and Pollak, P. (2002). Postoperative management of subthalamic nucleus stimulation for Parkinson's disease. Mov. Disord. 17(Suppl. 3), S188-S197.

Krack, P., Pollak, P., Limousin, P., Hoffmann, D., Benazzouz, A., Le Bas, J. F., Koudsie, A., and Benabid, A. L. (1998a). Opposite motor effects of pallidal stimulation in Parkinson's disease. Ann. Neurol. 43, 180-192.

Krack, P., Pollak, P., Limousin, P., Hoffmann, D., Xie, J., Benazzouz, A., and Benabid, A. L. (1998b). Subthalamic nucleus or internal pallidal stimulation in young onset Parkinson's disease. Brain 121(Pt 3), 451-457.

Krause, M., Fogel, W., Heck, A., Hacke, W., Bonsanto, M., Trenkwalder, C., and Tronnier, V. (2001). Deep brain stimulation for the treatment of Parkinson's disease: subthalamic nucleus versus globus pallidus internus. J. Neurol. Neurosurg. Psychiatr. 70, 464-470.

Krause, M., Fogel, W., Kloss, M., Rasche, D., Volkmann, J., and Tronnier, V. (2004a). Pallidal stimulation for dystonia. Neurosurgery 55, 1361-1368; discussion 1368-1370. 
Krause, M., Fogel, W., Mayer, P., Kloss, M., and Tronnier, V. (2004b). Chronic inhibition of the subthalamic nucleus in Parkinson's disease. J. Neurol. Sci. 219, 119-124.

Krauss, J. K., Loher, T. J., Weigel, R., Capelle, H. H., Weber, S., and Burgunder, J. M. (2003). Chronic stimulation of the globus pallidus internus for treatment of non-dYT1 generalized dystonia and choreoathetosis: 2-year follow up. J. Neurosurg. 98, 785-792.

Krauss, J. K., Mohadjer, M., Nobbe, F., and Mundinger, F. (1994). The treatment of posttraumatic tremor by stereotactic surgery. Symptomatic and functional outcome in a series of 35 patients. J. Neurosurg. 80, 810-819.

Krauss, J. K., Pohle, T., Weber, S., Ozdoba, C., and Burgunder, J. M. (1999). Bilateral stimulation of globus pallidus internus for treatment of cervical dystonia. Lancet 354, 837-838.

Krauss, J. K., Wakhloo, A. K., Nobbe, F., Trankle, R., Mundinger, F., and Seeger, W. (1995). Lesion of dentatothalamic pathways in severe posttraumatic tremor. Neurol. Res. 17, 409-416.

Kumar, R., Lang, A. E., Rodriguez-Oroz, M. C., Lozano, A. M., Limousin, P., Pollak, P., Benabid, A. L., Guridi, J., Ramos, E., Van Der Linden, C., Vandewalle, A., Caemaert, J., Lannoo, E., Van Den Abbeele, D., Vingerhoets, G., Wolters, M., and Obeso, J. A. (2000). Deep brain stimulation of the globus pallidus pars interna in advanced Parkinson's disease. $\mathrm{Neu}$ rology 55, S34-S39.

Kumar, R., Lozano, A. M., Kim, Y. J., Hutchison, W. D., Sime, E., Halket, E., and Lang, A. E. (1998). Double-blind evaluation of subthalamic nucleus deep brain stimulation in advanced Parkinson's disease. Neurology 51, 850-855.

Kupsch, A., Benecke, R., Muller, J., Trottenberg, T., Schneider, G. H., Poewe, W., Eisner, W., Wolters, A., Muller, J. U., Deuschl, G., Pinsker, M. O., Skogseid, I. M., Roeste, G. K., Vollmer-Haase, J., Brentrup, A., Krause, M., Tronnier, V., Schnitzler, A., Voges, J., Nikkhah, G., Vesper, J., Naumann, M., and Volkmann, J. (2006). Pallidal deep-brain stimulation in primary generalized or segmental dystonia. N. Engl. J. Med.355, 1978-1990.

Lagrange, E., Krack, P., Moro, E., Ardouin, C., Van Blercom, N., Chabardes, S., Benabid, A. L., and Pollak, P. (2002). Bilateral subthalamic nucleus stimulation improves health-related quality of life in PD. Neurology 59, 1976-1978.

Laitinen, L. V., Bergenheim, A. T., and Hariz, M. I. (1992). Leksell's posteroventral pallidotomy in the treatment of Parkinson's disease. J. Neurosurg. 76, 53-61.

Lang, A. E., and Lozano, A. M. (1998). Parkinson's disease. First of two parts. N. Engl. J. Med. 339, 1044-1053.

Lee, K. H., Blaha, C. D., Harris, B. T., Cooper, S., Hitti, F. L., Leiter, J. C., Roberts, D. W., and Kim, U. (2006). Dopamine efflux in the rat striatum evoked by electrical stimulation of the subthalamic nucleus: potential mechanism of action in Parkinson's disease. Eur. J. Neurosci. 23, 1005-1014.

Lezcano, E., Gomez-Esteban, J. C., Zarranz, J. J., Lambarri, I., Madoz, P., Bilbao, G., Pomposo, I., and Garibi, J. (2004). Improvement in quality of life in patients with advanced Parkinson's disease following bilateral deep-brain stimulation in subthalamic nucleus. Eur. J. Neurol. 11, 451-454.

Limousin, P., Krack, P., Pollak, P., Benazzouz, A., Ardouin, C., Hoffmann, D., and Benabid, A. L. (1998). Electrical stimulation of the subthalamic nucleus in advanced Parkinson's disease. N. Engl. J. Med. 339, 1105-1111.

Limousin, P., and Martinez-Torres, I. (2008). Deep brain stimulation for Parkinson's disease. Neurotherapeutics 5, 309-319.

Limousin, P., Pollak, P., Benazzouz, A., Hoffmann, D., Le Bas, J. F., Broussolle, E., Perret, J. E., and Benabid, A. L. (1995). Effect of parkinsonian signs and symptoms of bilateral subthalamic nucleus stimulation. Lancet 345, 91-95.

Limousin, P., Speelman, J. D., Gielen, F., and Janssens, M. (1999). Multicentre European study of thalamic stimulation in parkinsonian and essential tremor. J. Neurol. Neurosurg. Psychiatr. 66, 289-296.

Limousin-Dowsey, P., Pollak, P., Van Blercom, N., Krack, P., Benazzouz, A., and Benabid, A. (1999). Thalamic, subthalamic nucleus and internal pallidum stimulation in Parkinson's disease. J. Neurol. 246(Suppl. 2), II42-II45.

Loher, T. J., Burgunder, J. M., Weber, S., Sommerhalder, R., and Krauss, J. K. (2002). Effect of chronic pallidal deep brain stimulation on off period dystonia and sensory symptoms in advanced Parkinson's disease. J. Neurol. Neurosurg. Psychiatr. 73, 395-399.
Louis, E. D., Thawani, S. P., and Andrews, H. F. (2009). Prevalence of essential tremor in a multiethnic, community-based study in northern Manhattan, New York, N.Y. Neuroepidemiology 32, 208-214.

Lozano, A. M. (2000). Vim thalamic stimulation for tremor. Arch. Med. Res. 31, 266-269.

Lozano, A. M., and Abosch, A. (2004). Pallidal stimulation for dystonia. Adv. Neurol. 94, 301-308.

Lozano, A. M., Kumar, R., Gross, R. E. Giladi, N., Hutchison, W. D., Dostrovsky, J. O., and Lang, A. E. (1997). Globus pallidus internus pallidotomy for generalized dystonia. Mov. Disord. 12, 865-870.

Lyons, K. E., and Pahwa, R. (2005). Long-term benefits in quality of life provided by bilateral subthalamic stimulation in patients with Parkinson disease. J. Neurosurg. 103 252-255.

Lyons, K. E., Wilkinson, S. B., Troster, A. I., and Pahwa, R. (2002). Long-term efficacy of globus pallidus stimulation for the treatment of Parkinson's disease. Stereotact. Funct. Neurosurg. 79, 214-220.

Magarinos-Ascone, C., Pazo, J. H., Macadar, O., and Buno, W. (2002). High-frequency stimulation of the subthalamic nucleus silences subthalamic neurons: a possible cellular mechanism in Parkinson's disease. Neuroscience 115, 1109-1117.

Martinez-Martin, P., Valldeoriola, F. Tolosa, E., Pilleri, M., Molinuevo, J. L., Rumia, J., and Ferrer, E. (2002). Bilateral subthalamic nucleus stimulation and quality of life in advanced Parkinson's disease. Mov. Disord. 17, 372-377.

Matsumoto, K., Asano, T., Baba, T., Miyamoto, T., and Ohmoto, T. (1976). Long-term follow-up results of bilateral thalamotomy for parkinsonism. Appl. Neurophysiol. 39, 257-260.

Medtronic. (2011). About Medtronic Deep Brain Stimulation Therapy. Available at: http://www.medtron icdbs.com/parkinsons/about/index. htm [accessed October 21, 2011].

Miocinovic, S., Parent, M., Butson, C. R., Hahn, P. J., Russo, G. S., Vitek, J. L., and Mcintyre, C. C. (2006). Computational analysis of subthalamic nucleus and lenticular fasciculus activation during therapeutic deep brain stimulation. J. Neurophysiol. 96, 1569-1580.

Molinuevo, J. L., Valldeoriola, F., Tolosa, E., Rumia, J., Valls-Sole, J., Roldan, H., and Ferrer, E. (2000). Levodopa withdrawal after bilateral subthalamic nucleus stimulation in advanced
Parkinson disease. Arch. Neurol. 57, 983-988.

Moro, E., Scerrati, M., Romito, L. M., Roselli, R., Tonali, P., and Albanese, A. (1999). Chronic subthalamic nucleus stimulation reduces medication requirements in Parkinson's disease. Neurology 53, 85-90.

Mueller, J., Skogseid, I. M., Benecke, R., Kupsch, A., Trottenberg, T. Poewe, W., Schneider, G. H., Eisner, W., Wolters, A., Muller, J. U., Deuschl, G., Pinsker, M. O., Roeste, G. K., Vollmer-Haase, J., Brentrup, A., Krause, M., Tronnier, V., Schnitzler, A., Voges, J., Nikkhah, G., Vesper, J., Naumann, M., and Volkmann, J. (2007). Pallidal deep brain stimulation improves quality of life in segmental and generalized dystonia: results from a prospective, randomized shamcontrolled trial. Mov. Disord. 23, 131-134.

Muta, D., Goto, S., Nishikawa, S., Hamasaki, T., Ushio, Y., Inoue, N., and Mita, S. (2001). Bilateral pallidal stimulation for idiopathic segmental axial dystonia advanced from Meige syndrome refractory to bilateral thalamotomy. Mov. Disord. 16, 774-777.

Nandhagopal, R., Mak, E., Schulzer, M., Mckenzie, J., Mccormick, S., Sossi, V., Ruth, T. J., Strongosky, A., Farrer, M. J., Wszolek, Z. K., and Stoessl, A. J. (2008). Progression of dopaminergic dysfunction in a LRRK2 kindred: a multitracer PET study. Neurology 71, 1790-1795.

Nguyen, J. P., and Degos, J. D. (1993). Thalamic stimulation and proximal tremor. A specific target in the nucleus ventrointermedius thalami. Arch. Neurol. 50, 498-500.

Nutt, J. G., and Wooten, G. F. (2005). Clinical practice. Diagnosis and initial management of Parkinson's disease. N. Engl. J. Med. 353, 1021-1027.

Ohye, C., Hirai, T., Miyazaki, M., Shibazaki, T., and Nakajima, $H$. (1982). Vim thalamotomy for the treatment of various kinds of tremor. Appl. Neurophysiol. 45, 275-280.

Olanow, C. W., and Stern, M. B. (2008). Parkinson's disease: unresolved issues. Ann. Neurol. 64(Suppl. 2), S1-S2.

Ondo, W., Almaguer, M., Jankovic, J., and Simpson, R. K. (2001). Thalamic deep brain stimulation: comparison between unilateral and bilateral placement. Arch. Neurol. 58, 218-222. 
Ondo, W., Jankovic, J., Schwartz, K., Almaguer, M., and Simpson, R. K. (1998). Unilateral thalamic deep brain stimulation for refractory essential tremor and Parkinson's disease tremor. Neurology 51, 1063-1069.

Ory-Magne, F., Brefel-Courbon, C., Simonetta-Moreau, M., Fabre, N., Lotterie, J. A., Chaynes, P., Berry, I., Lazorthes, Y., and Rascol, O. (2007). Does ageing influence deep brain stimulation outcomes in Parkinson's disease? Mov. Disord. 22, 1457-1463.

Ostrem, J. L., Marks, W. J. Jr., Volz, M. M., Heath, S. L., and Starr, P. A. (2007). Pallidal deep brain stimulation in patients with cranial-cervical dystonia (Meige syndrome). Mov. Disord. 22, 1885-1891.

Ostrem, J. L., and Starr, P. A. (2008). Treatment of dystonia with deep brain stimulation. Neurotherapeutics 5, 320-330.

Pahwa, R., Lyons, K. E., Wilkinson, S. B., Simpson, R. K. Jr., Ondo, W. G., Tarsy, D., Norregaard, T., Hubble, J. P., Smith, D. A., Hauser, R. A., and Jankovic, J. (2006). Long-term evaluation of deep brain stimulation of the thalamus. J. Neurosurg. 104, 506-512.

Pahwa, R., Lyons, K. L., Wilkinson, S. B., Carpenter, M. A., Troster, A. I., Searl, J. P., Overman, J., Pickering, S., and Koller, W. C. (1999). Bilateral thalamic stimulation for the treatment of essential tremor. Neurology 53, 1447-1450.

Parent, A., and Hazrati, L. N. (1995). Functional anatomy of the basal ganglia. I. The cortico-basal gangliathalamo-cortical loop. Brain Res. Brain Res. Rev. 20, 91-127.

Peppe, A., Gasbarra, A., Stefani, A., Chiavalon, C., Pierantozzi, M., Fermi, E., Stanzione, P., Caltagirone, C., and Mazzone, P. (2008). Deep brain stimulation of $\mathrm{CM} / \mathrm{PF}$ of thalamus could be the new elective target for tremor in advanced Parkinson's disease? Parkinsonism Relat. Disord. 14, 501-504.

Peppe, A., Pierantozzi, M., Bassi, A., Altibrandi, M. G., Brusa, L., Stefani, A., Stanzione, P., and Mazzone, P. (2004). Stimulation of the subthalamic nucleus compared with the globus pallidus internus in patients with Parkinson disease. J. Neurosurg. 101, 195-200.

Pinter, M. M., Alesch, F., Murg, M., Seiwald, M., Helscher, R. J., and Binder, H. (1999). Deep brain stimulation of the subthalamic nucleus for control of extrapyramidal features in advanced idiopathic Parkinson's disease: one year follow-up. J. Neural Transm. 106, 693-709.
Pittock, S. J., Mcclelland, R. L., Mayr, W. T., Rodriguez, M., and Matsumoto, J. Y. (2004). Prevalence of tremor in multiple sclerosis and associated disability in the Olmsted County population. Mov. Disord. 19, 1482-1485.

Plaha, P., Ben-Shlomo, Y., Patel, N. K., and Gill, S. S. (2006). Stimulation of the caudal zona incerta is superior to stimulation of the subthalamic nucleus in improving contralateral parkinsonism. Brain 129, 1732-1747.

Poewe, W. (2009). Treatments for Parkinson disease - past achievements and current clinical needs. Neurology 72, S65-S73.

Pollak, P., Fraix, V., Krack, P., Moro, E., Mendes, A., Chabardes, S., Koudsie, A., and Benabid, A. L. (2002). Treatment results: Parkinson's disease. Mov. Disord. 17(Suppl. 3), S75-S83.

Putnam, T. (1938). Relief from unilateral paralysis agitans by section of the lateral pyramidal tract. Arch. Neurol. Psychiatry 40, 1049-1050.

Putzke, J. D., Uitti, R. J., Obwegeser, A. A., Wszolek, Z. K., and Wharen, R. E. (2005). Bilateral thalamic deep brain stimulation: midline tremor control. J. Neurol. Neurosurg. Psychiatr. 76, 684-690.

Rehncrona, S., Johnels, B., Widner, H., Tornqvist, A. L., Hariz, M., and Sydow, O. (2003). Long-term efficacy of thalamic deep brain stimulation for tremor: double-blind assessments. Mov. Disord. 18, 163-170.

Remple, M. S., Sarpong, Y., and Neimat, J. S. (2008). Frontiers in the surgical treatment of Parkinson's disease. Expert Rev. Neurother. 8, 897-906.

Robledo, P., and Feger, J. (1990). Excitatory influence of rat subthalamic nucleus to substantia nigra pars reticulata and the pallidal complex: electrophysiological data. Brain Res. 518, 47-54.

Rodrigues, J. P., Walters, S. E., Watson, P., Stell, R., and Mastaglia, F. L. (2007a). Globus pallidus stimulation improves both motor and nonmotor aspects of quality of life in advanced Parkinson's disease. Mov. Disord. 22, 1866-1870.

Rodrigues, J. P., Walters, S. E., Watson, P., Stell, R., and Mastaglia, F. L. (2007b). Globus pallidus stimulation in advanced Parkinson's disease. J. Clin. Neurosci. 14, 208-215.

Rodriguez-Oroz, M. C., Obeso, J. A., Lang, A. E., Houeto, J. L., Pollak, P., Rehncrona, S., Kulisevsky, J., Albanese, A., Volkmann, J., Hariz, M. I., Quinn, N. P., Speelman, J. D., Guridi, J., Zamarbide, I., Gironell, A., Molet, J., Pascual-Sedano, B., Pidoux, B., Bonnet, A. M., Agid, Y.,
Xie, J., Benabid, A. L., Lozano, A. M., Saint-Cyr, J., Romito, L., Contarino, M. F., Scerrati, M., Fraix, V., and Van Blercom, N. (2005). Bilateral deep brain stimulation in Parkinson's disease: a multicentre study with 4 years follow-up. Brain 128, 2240-2249.

Schrag, A., Jahanshahi, M., and Quinn, N. (2000). What contributes to quality of life in patients with Parkinson's disease? J. Neurol. Neurosurg. Psychiatr. 69, 308-312.

Schupbach, M., Gargiulo, M., Welter, M. L., Mallet, L., Behar, C., Houeto, J. L., Maltete, D., Mesnage, V., and Agid, Y. (2006). Neurosurgery in Parkinson disease: a distressed mind in a repaired body? Neurology 66, 1811-1816.

Schupbach, W. M., Chastan, N., Welter, M. L., Houeto, J. L., Mesnage, V., Bonnet, A. M., Czernecki, V., Maltete, D., Hartmann, A., Mallet, L., Pidoux, B., Dormont, D., Navarro, S., Cornu, P., Mallet, A., and Agid, Y. (2005). Stimulation of the subthalamic nucleus in Parkinson's disease: a 5 year follow up. J. Neurol. Neurosurg. Psychiatr. 76, 1640-1644.

Schuurman, P. R., Bosch, D. A., Merkus, M. P., and Speelman, J. D. (2008) Long-term follow-up of thalamic stimulation versus thalamotomy for tremor suppression. Mov. Disord. 23 , 1146-1153.

Schuurman, P. R., Bruins, J., Merkus, M. P., Bosch, D. A., and Speelman, J. D. (2002). A comparison of neuropsychological effects of thalamotomy and thalamic stimulation. Neurology 59, 1232-1239.

Seif, C., Herzog, J., Van Der Horst, C., Schrader, B., Volkmann, J., Deuschl, G., Juenemann, K. P., and Braun, P. M. (2004). Effect of subthalamic deep brain stimulation on the function of the urinary bladder. Ann. Neurol. 55, 118-120.

Shon, Y. M., Chang, S. Y., Tye, S. J., Kimble, C. J., Bennet, K. E., Blaha, C. D. and Lee, K. H. (2009). Comonitoring of adenosine and dopamine using the wireless instantaneous neurotransmitter concentration system: proof of principle. J. Neurosurg. 112 , 539-548.

Shon, Y. M., Chang, S. Y., Tye, S. J., Kimble, C. J., Bennet, K. E., Blaha, C. D., and Lee, K. H. (2010a). Comonitoring of adenosine and dopamine using the wireless instantaneous neurotransmitter concentration system: proof of principle. J. Neurosurg. $112,539-548$

Shon, Y. M., Lee, K. H., Goerss, S. J., Kim, I. Y., Kimble, C., Van Gompel, J. J., Bennet, K., Blaha, C. D., and Chang, S. Y. (2010b). High frequency stimulation of the subthalamic nucleus evokes striatal dopamine release in a large animal model of human DBS neurosurgery. Neurosci. Lett. 475, 136-140.

Speelman, J. D., and Van Manen, J. (1984). Stereotactic thalamotomy for the relief of intention tremor of multiple sclerosis. J. Neurol. Neurosurg. Psychiatr. 47, 596-599.

Starr, P. A., Turner, R. S., Rau, G., Lindsey, N., Heath, S., Volz, M., Ostrem, J. L., and Marks, W. J. Jr. (2006). Microelectrode-guided implantation of deep brain stimulators into the globus pallidus internus for dystonia: techniques, electrode locations, and outcomes. $J$. Neurosurg. 104, 488-501.

Stefani, A., Lozano, A. M., Peppe, A., Stanzione, P., Galati, S., Tropepi, D., Pierantozzi, M., Brusa, L., Scarnati, E., and Mazzone, P. (2007). Bilateral deep brain stimulation of the pedunculopontine and subthalamic nuclei in severe Parkinson's disease. Brain 130, 1596-1607.

Svennilson, E., Torvik, A., Lowe, R., and Leksell, L. (1960). Treatment of parkinsonism by stereotatic thermolesions in the pallidal region. A clinical evaluation of 81 cases. Acta Psychiatr. Scand. 35, 358-377.

Sydow, O., Thobois, S., Alesch, F., and Speelman, J. D. (2003). Multicentre European study of thalamic stimulation in essential tremor: a six year follow up. J. Neurol. Neurosurg. Psychiatr. 74, 1387-1391.

Taha, J. M., Janszen, M. A., and Favre, J. (1999). Thalamic deep brain stimulation for the treatment of head, voice, and bilateral limb tremor. $J$. Neurosurg. 91, 68-72.

Tasker, R. R. (1998). Deep brain stimulation is preferable to thalamotomy for tremor suppression. Surg. Neurol.49, 145-153; discussion 153-144.

Tisch, S., Zrinzo, L., Limousin, P., Bhatia, K. P., Quinn, N., Ashkan, K. and Hariz, M. (2007). Effect of electrode contact location on clinical efficacy of pallidal deep brain stimulation in primary generalised dystonia. J. Neurol. Neurosurg. Psychiatr. 78, 1314-1319.

Toettcher, J. E., Voigt, C. A., Weiner, O. D., and Lim, W. A. (2011). The promise of optogenetics in cell biology: interrogating molecular circuits in space and time. Nat. Methods 8, 35-38.

Tye, S. J., Frye, M. A., and Lee, K. H. (2009). Disrupting disordered neurocircuitry: treating refractory psychiatric illness with neuromodulation. Mayo Clin. Proc. 84, 522-532. 
Van Gompel, J. J., Chang, S. Y., Goerss, S. J., Kim, I. Y., Kimble, C., Bennet, K. E., and Lee, K. H. (2010). Development of intraoperative electrochemical detection: wireless instantaneous neurochemical concentration sensor for deep brain stimulation feedback. Neurosurg. Focus 29, E6.

Vidailhet, M., Vercueil, L., Houeto, J. L., Krystkowiak, P., Benabid, A. L., Cornu, P., Lagrange, C., Tezenas Du Montcel, S., Dormont, D., Grand, S., Blond, S., Detante, O., Pillon, B., Ardouin, C., Agid, Y., Destee, A., and Pollak, P. (2005). Bilateral deepbrain stimulation of the globus pallidus in primary generalized dystonia. N. Engl. J. Med. 352, 459-467.

Vidailhet, M., Vercueil, L., Houeto, J. L., Krystkowiak, P., Lagrange, C., Yelnik, J., Bardinet, E., Benabid, A. L., Navarro, S., Dormont, D., Grand, S., Blond, S., Ardouin, C., Pillon, B., Dujardin, K., Hahn-Barma, V., Agid, Y., Destee, A., and Pollak, P. (2007). Bilateral, pallidal, deep-brain stimulation in primary generalised dystonia: a prospective 3 year follow-up study. Lancet Neurol. 6, 223-229.

Vingerhoets, G., Lannoo, E., Van Der Linden, C., Caemaert, J., Vandewalle, V., Van Den Abbeele, D., and Wolters, M. (1999). Changes in quality of life following unilateral pallidal stimulation in Parkinson's disease. J. Psychosom. Res. 46, 247-255.

Vitek, J. L., Zhang, J., Evatt, M., Mewes, K., Delong, M. R., Hashimoto, T., Triche, S., and Bakay, R. A. (1998). GPi pallidotomy for dystonia: clinical outcome and neuronal activity. Adv. Neurol. 78, 211-219.

Volkmann, J., Allert, N., Voges, J., Sturm, V., Schnitzler, A., and Freund,
H. J. (2004). Long-term results of bilateral pallidal stimulation in Parkinson's disease. Ann. Neurol. 55, 871-875.

Volkmann, J., Allert, N., Voges, J., Weiss, P. H., Freund, H. J., and Sturm, V. (2001). Safety and efficacy of pallidal or subthalamic nucleus stimulation in advanced PD. Neurology 56, 548-551.

Volkmann, J., Sturm, V., Weiss, P., Kappler, J., Voges, J., Koulousakis, A., Lehrke, R., Hefter, H., and Freund, H. J. (1998). Bilateral high-frequency stimulation of the internal globus pallidus in advanced Parkinson's disease. Ann. Neurol. 44, 953-961.

Walker, A. E. (1952). Cerebral pedunculotomy for the relief of involuntary movements. II. Parkinsonian tremor. J. Nerv. Ment. Dis. 116, 766-775.

Wider, C., Pollo, C., Bloch, J., Burkhard, P. R., and Vingerhoets, F. J. (2008). Long-term outcome of 50 consecutive Parkinson's disease patients treated with subthalamic deep brain stimulation. Parkinsonism Relat. Disord. 14, 114-119.

Windels, F., Bruet, N., Poupard, A., Feuerstein, C., Bertrand, A., and Savasta, M. (2003). Influence of the frequency parameter on extracellular glutamate and gammaaminobutyric acid in substantia nigra and globus pallidus during electrical stimulation of subthalamic nucleus in rats. J. Neurosci. Res. 72, 259-267.

Windels, F., Bruet, N., Poupard, A., Urbain, N., Chouvet, G., Feuerstein, C., and Savasta, M. (2000). Effects of high frequency stimulation of subthalamic nucleus on extracellular glutamate and GABA in substantia nigra and globus pallidus in the normal rat. Eur. J. Neurosci. 12, 4141-4146.

Winge, K., Nielsen, K. K., Stimpel, H., Lokkegaard, A., Jensen, S. R., and Werdelin, L. (2007). Lower urinary tract symptoms and bladder control in advanced Parkinson's disease: effects of deep brain stimulation in the subthalamic nucleus. Mov. Disord. 22, 220-225.

Witjas, T., Kaphan, E., Regis, J., Jouve, E., Cherif, A. A., Peragut, J. C., and Azulay, J. P. (2007). Effects of chronic subthalamic stimulation on nonmotor fluctuations in Parkinson's disease. Mov. Disord. 22, 1729-1734.

Woods, S. P., Fields, J. A., Lyons, K. E., Koller, W. C., Wilkinson, S. B., Pahwa, R., and Troster, A. I. (2001). Neuropsychological and quality of life changes following unilateral thalamic deep brain stimulation in Parkinson's disease: a one-year follow-up. Acta Neurochir (Wien) 143, 1273-1277; discussion 1278

Yap, L., Kouyialis, A., and Varma, T. R. (2007). Stereotactic neurosurgery for disabling tremor in multiple sclerosis: thalamotomy or deep brain stimulation? Br. J. Neurosurg. 21, 349-354.

Yianni, J., Bain, P., Giladi, N., Auca, M., Gregory, R., Joint, C., Nandi, D., Stein, J., Scott, R., and Aziz, T. (2003). Globus pallidus internus deep brain stimulation for dystonic conditions: a prospective audit. Mov. Disord. 18 436-442.

Zibetti, M., Torre, E., Cinquepalmi, A., Rosso, M., Ducati, A., Bergamasco, B., Lanotte, M., and Lopiano, L. (2007). Motor and nonmotor symptom follow-up in parkinsonian patients after deep brain stimulation of the subthalamic nucleus. Eur. Neurol. 58, 218-223.

Zirh, A., Reich, S. G., Dougherty, P. M. and Lenz, F. A. (1999). Stereotactic thalamotomy in the treatment of essential tremor of the upper extremity: reassessment including a blinded measure of outcome. J. Neurol. Neurosurg. Psychiatr. 66, 772-775.

Zorzi, G., Marras, C., Nardocci, N., Franzini, A., Chiapparini, L., Maccagnano, E., Angelini, L., Caldiroli, D., and Broggi, G. (2005). Stimulation of the globus pallidus internus for childhoodonset dystonia. Mov. Disord. 20, 1194-1200.

Conflict of Interest Statement: The authors declare that the research was conducted in the absence of any commercial or financial relationships that could be construed as a potential conflict of interest.

Received: 05 August 2011; accepted: 07 October 2011; published online: 09 November 2011.

Citation: Schiefer TK, Matsumoto JY and Lee KH (2011) Moving forward: advances in the treatment of movement disorders with deep brain stimulation. Front. Integr. Neurosci. 5:69. doi: 10.3389/fnint.2011.00069

Copyright (c) 2011 Schiefer, Matsumoto and Lee. This is an open-access article subject to a non-exclusive license between the authors and Frontiers Media $S A$, which permits use, distribution and reproduction in other forums, provided the original authors and source are credited and other Frontiers conditions are complied with. 